MITIKA KURIBAYASHI HAGIWARA Dr. 69

$\varnothing$

\title{
ESTUDO COMPARATIVO ENTRE AS \\ REACOES DE SOROAGLUTINAÇÁO MICROSCÓPICA E DE FIXACAO DO COMPLEMENTO NA LEPTOSPIROSE CANINA EXPERIMENTAL PELOS SOROTIPOS icterohaemorrhagiae E canicola
}

Tese apresentada à

Faculdade de Saúde Pública da Universidado de São Paulo, Departamento de Prática de Saúde Pública, para a obtenção do título de Doutor.

Orientador: Prof. Dr. Gil Vianna Paim

São Paulo 1979 
A minha mãe,

exemplo de dignidade,

dedicaçāo è perseverança.

Ao Susumu,

Jun e

Yumi . 


\section{AGRADECIMENTOS}

Ao Prof. Dr. Gil Vianna Paim, pela acolhida, confiança e orientação que nos foram dispensadas, durante to do o período de pós-graduação.

Ao Prof. Dr. Carlos Almeida Santa Rosa, pela dedicação, estímulo e amizade com que nos acompanhou na execu ção deste trabalho.

Ao Prof. Dr. Aramis Augusto Pinto, pela inestimável colaboração na execução das reações de fixação do complemento.

Ao Prof. Dr. Eduardo Harry Birgel, pelo constante estí mulo, sugestões apresentadas e revisão dos originais. 
Aos colegas Carlos Eduardo Larsson e Maria Helena M. A. Larsson, pela valiosa colaboração.

Ao Dr. Paulo Hideki Yassuda, pelo fornecimento das amos tras do sorotipo icterohaemorrhagiae e canicola, ut $\underline{\mathbf{i}}$ lizadas na inoculação experimental.

A Dra. Maria de Lourdes Aguiar Bonadia Reichmann, do Bio tério do Hospital do Servidor Público Estadual, pela doação do soro de cobaias, imprescindível na reação de fixação do complemento.

Ao Dr. Antonio Roberto Correa, do Laboratōrio Biovet Ltda, pela doação das vacinas de cinomose e hepatite.

A Organização Granja Seleta Ltda, pela doação de sangue de coelho utilizado no enriquecimento dos meios de cultura.

Ao Serviço Médico Cirúrgico e Hospitalar da Faculdade de Medicina Veterināria e Zootecnia da Universidade de São Paulo, pelas facilidades concedidas na obtenção e manutençāo dos animais experimentais.

A Sra. Maria Luiza Rigo Pasquarelli e Srta. Daisy Pires Noronha, pela colaboração na revisãn e ordenação das Referências Bibliográficas.

A Sra. Regina Mieko Sakata Mirandola e Srta. Magda Nunes, pelo inestimävel auxílio prestado na execução técni ca deste trabalho.

Ao Sr. Francisco Vieira de Camargo e Sra. Altiva Lima Rodrigues, pelos serviços prestados. 
RESUMO.

Com a finalidade de se analisar a dinâmica da evo lução dos anticorpos na fase aguda da infecção, através das rea çōes de soroaglutinação microscōpica e de fixação do complemen to, trinta animais foram inoculados experimentalmente com lep tospiras patogènicas, sendo quinze com o sorotipo icterohae morrhagiae e quinze com o sorotipo canicola. Procurou-se tam bém avaliar a potencialidade do emprego dos antígenos prepara dos com amostras de leptospiras aquícolas estirpes Patoc I, Ru fino e Buenos Aires, em ambas as reações.

Os anticorpos fixadores do complemento foram observa dos na circulação sanguínea a partir do $4^{\circ}$ dia após a inocula ção em ambos os grupos de animais, enquanto as aglutininas fo ram detectadas a partir do $7^{\circ}$ dia. Estas persistem durante um período maior de tempo, pois $50 \%$ dos animais inaculados com o sorotipo icterohaemorrhagiae apresentaram anticorpos circulan tes no $56^{\circ}$ dia após a inoculação e $80 \%$ dos cães inoculados com - sorotipo canicola, no $63^{\circ}$ dia pós-infecção. Nessa oportunida de, os anticorpos fixadores do complemento não foram observados nos sorós dos animais de ambos os grupos.

As estirpes Patoc $I$ e Rufino não foram eficientes em revelar anticorpos circulantes em ambos os grupos experimentais tanto pela reação de soroaglutinação microscópica como pela rea ção de fixação do complemento, em proporções que justifiquem seu emprego como antígeno único. Entretinto, $87^{\circ}$ dos cães inocula dos com o sorotipo icterohaemorrhagiae e $80 \%$ dos cães inocula dos com o sorotipo canicola foram reagentes quando se empregou a estirpe Buenos Aires nas reaçōes de soroaglutinação microscó pica e de fixaçāo do complemento. 
In order to evaluate the antibody response to pathoge nic leptospira from both serotypes icterohaemorrhagiae and cani cola, dogs were experimentally inoculated with these two seroty pes. Each of the serotypes were inoculated in 15 dogs and the antibody response in the acute phase of infection was followed using agglutination, and complement fixation tests. These tests were also performed using non pathogenic leptospira such as $\mathrm{Pa}$ toc I, Rufino and Buenos Aires.

Complement fixing antibodies were detected in both groups, at the $4^{\text {th }}$ day post-infection and agglutinins only appeared in circulation at the $7^{\text {th }}$ day post-infection when ho mologous antigens were used.

On the $63^{\text {rd }}$ day post-infection with canicola serotype and on the $56^{\text {th }}$ day post-infection with the serotype icterohae morrhagiae complement fixing antibody could no longer be detect ed but, in both experimental groups, specific agglutinins were present in significant tittles.

The antigens Patoc $I$ and Rufino were inefficient to detect circulating antibodies in experimentally infected an ma1s. However, when the Buenos Aires antigen was used 87 per cent of the animals infected with the serotype icterohaemorrhagiae and 80 per cent of the animals infected with the serotype canicola showed significant tittles of antibody. 


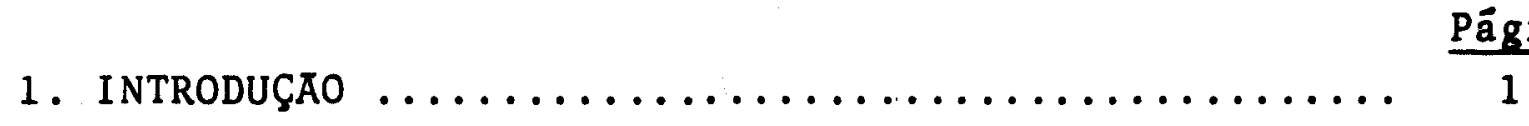

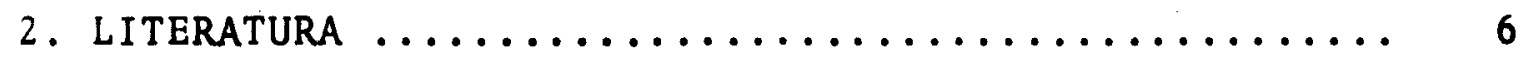

3. MATERIAL E METODOS ...................... 14

3.1. Inoculação experimental .................. 14

3.1.1. Seleção dos animais ............. 14

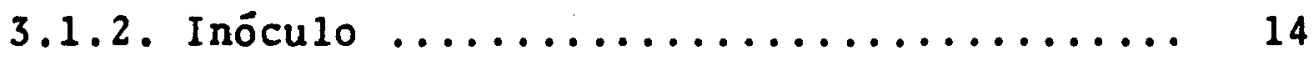

3.1.3. Constituição dos grupos ............ 15

3.1.4. Coleta de sangue e de urina .......... 16

3.2. Reação de soroaglutinação microscōpica ....... 17

3.2.1. Antigenos .................. 17

3.2.2. Técnica da soroaglutinação microscópica. 17

3.3. Reação de fixação do complemento ........... 19

3.3.1. Hemácias de carneiro .............. 19

3.3.2. Hemolisina anti-hemäcias de carneiro ... 19

3.3.3. Complemento ................. 19

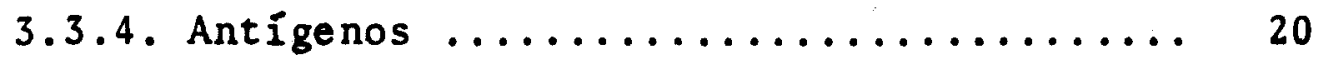

3.3.5. Soros hiperimunes .............. 20

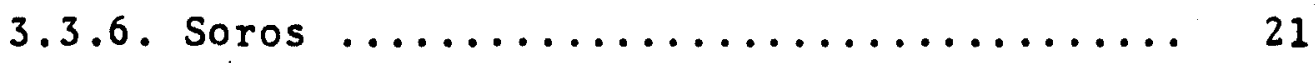

3.3.7. Técnica da reação de fixação do complemento ................... 21

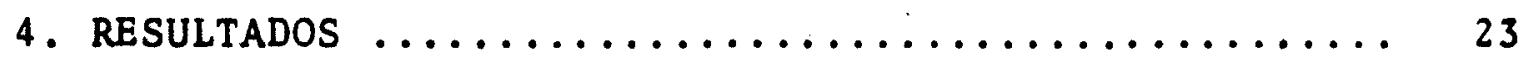

4.1. Reação de soroaglutinação microscópica e de fixação do complemento frente aos antígenos

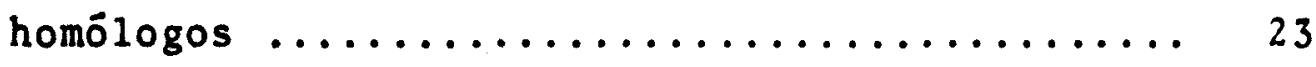

4.2. Reaçōes de soroaglutinação microscópica e fixação do complemento frente aos antígenos

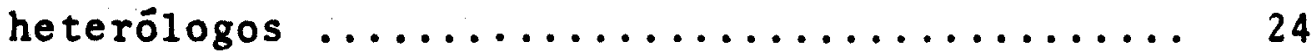

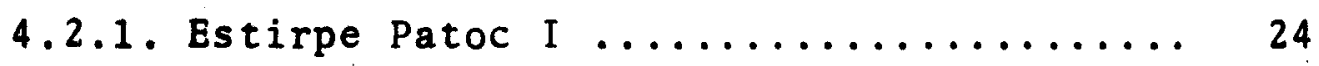

4.2.2. Estirpe Rufino ................ 25

4.2.3. Estirpe Buenos Aires ............ 25

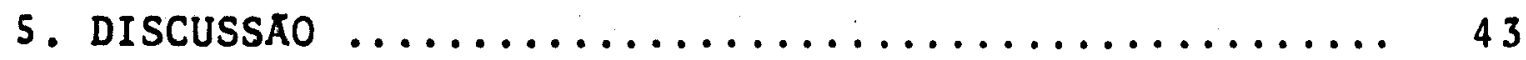

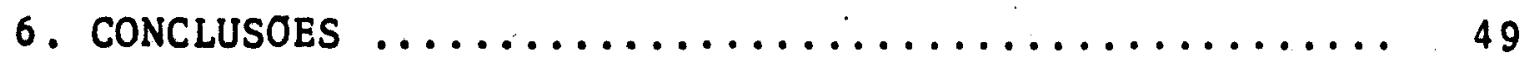

7. REFERENCIAS BIBLIOGRAFICAS $\ldots \ldots \ldots \ldots \ldots \ldots \ldots \ldots$ 
1. INTRODUCCAO.

A leptospirose é uma infecção largamente disse minada entre os animais domésticos e silvestres, assumindo con siderável importância como problema econômico e de saúde públi ca. E causada por um espiroqueta do gênero Leptospira do qual se conhecem pouco mais de 150 sorotipos, com caracteristicas morfológicas, biológicas e culturais idênticas 33 . A distribui ção dos sorotipos na natureza depende do ecossistema regional, existindo assim, de acordo com a ärea geográfica, focos natu rais de determinados sorotipos e uma certa especificidade de hospedeiro 47 .

Praticamente todos os animais domésticos, silves tres e o homem são suscetíveis, manifestando ou não os sintomas decorrentes da infeccão. Inúmeros animais domésticos. princí palmente os suínos, bovinos e caninos, bem como a maioria dos espécimes silvestres, entre os quais pode-se destacar os carní voros, roedores e marsupiais tornam-se, após a infecção, porta dores, disseminando o microrganismo ná natureza. A eliminação deste espiroqueta pela urina dos portadores ocorre por períodos que podem variar de poucas semanas até muitos meses entre os animais domésticos e por tôda a vida nos roedores. ${ }^{4}$.

A susceptibilidade do cão às infecções pelos di ferentes sorotipos de leptospira jả é conhecida de longa data, principalmente a que se refere aos sorotipos icterohaemorrha giae e canicola ${ }^{4}$. Este último apresenta uma real adaptação ao tecido renal do hospedeiro, tornando-se o cão portador e eli minando o espiroqueta pela urina, turante um grande período de tempo. A infecção pelos sorotipos icterohaemorrhagiae e canico 1a pode determinar o aparecimento de sintomas perfeitamente ca racterizados, embora a gravidade da doença possa sofrer inter ferência de fatores individuais. Muitos dos animais infectados são assintomáticos. Outros sorotipos também podem infectar os cães, determinando quadros mórbidos semelhantes, como também in 
fecçñes venígnas. Muitos sorotipos de leptospiras do complexo interrogans jā foram isolados de cães doentes ou portadores $s \underline{a}$ dios, além dos sorotipos icterohaemorrhagiae e canicola, poden do ser relacionados: australis, pomona, hebdomadis, autumalis. javanica, saxkoebing, seijoe, tarassovi, medanensis, bangkok,py rogenes, grippotyphosa, gem, paidjan e wewak 26,27. Existem tam bém evidências sorológicas de infecção por outros sorotipos co mo mitis, bratislava, poi, australis e butembo ${ }^{19}$.

Inquéritos sorológicos e isolamento do agente $e$ tiológico demonstram haver predominência dos sorotipos ictero haemorrhagiae e canicola, principalmente o ültimo, embora o cão seja suscetível à infecção por uma variedade muito grande de so rotipos. YASSUDA 55 (1979), em amplo estudo epidemiológico, a brangendo 1415 cāes de rua de São Paulo, isolou 35 amostras de leptospiras das quais 32 eram do sorotipo canicola, 2 do soroti po copenhageni e 1 amostra do sorotipo pomona.

A alta suscetibilidade do cão à infecção pelas leptospiras, aliada à frequência com que ocorre a condiçāo de portador renal apresentam particular interesse em saúde pública, devido ao convívio muito próximo desse animal com o homem. A leptospirose humana, durante muitos anos, considerada uma doen ça profissional própria de determinados grupos de indivíduos que, pelas caracteristicas ocupacionais tinham, em comum, 0 contato com os animais domésticos, silvestres ou seus excrementos ${ }^{49}$, a tualmente tem-se tornado mais frequente em crianças, estudantes e donas de casa, transmitida pelo contato com os cães 53 .

O diagnōstico etiológico da infecção ou da doen ça é feito normalmente através da determinação de anticorpos no sangue circulante $e$, mais raramente, pelo isolamento do agente em materiais biológicos como sangue, líquido cefalorraquidiano ou urina ${ }^{42}$. Após a morte do animal, pode-se conseguir o isola mento do espiroqueta, cultivando-se fragmentos dos rins.

A reação sorológica padrão, recomendada pela $0 \underline{\underline{Y}}$ ganizaçāo Mundial de Saúde ${ }^{33}$ e utilizada rotineiramente no diag 
nôstico da leptospịirose ê o teste de aglutinação microsčópica tretanto, este teste só pode ser realizado em poucos laborató rios, devido à necessidade de equipamentos especiais e de pos soal experiente, além de haver a necessidade da manutenção de culturas vivas de leptospiras dos sorotipos representativos de cada um dos sorogrupos patogênicos e de alguns sorogrupos de lep tospiras aquícolas. 0 ideal, então, seria uma reação de fácil execução e com um mínimo de sorotipos como antígenos, ou a utí lização de um antígeno único, que permitisse estabelecer o diag nóstico da infecção com facilidade e segurança, independenté dos sorotipos envolvidos.

Nos ültimos 20 anos, inúmeros trabalhos tem sido desenvolvidos $16,13,1,17,37$, procurando-se um antígeno com as características acima citadas. Observou-se que algumas amos tras de leptospiras aquicolas podem ser aglutinadas pelos soros de indivíduos reagentes às leptospiras patogênicas. Entre es tas, destacam-se as cepas Patoc I e São Paulo, sendo a primeira largamente utilizada no diagnóstico laboratorial da leptospiro se humana nas reações de aglutinação microscópica 17, 28, 15 , ou fixação de complemento $13,45,38$. Embora ambas produzem uma reação satisfatória com soros humanos, tal não acontece com 0 soro dos animais domésticos $2,13,31,44,40$. As razões dessa diferença no comportamento não são conhecidas, sugerindo-se en tretanto que, estaria relacionada às caracteristicas imunobioló gicas de cada espécie animal. Além do mais, cabe destacar que, a maioria dos soros animais positivos para leptospiras patogêni cas é obtida em inquéritos epidemiológicos, desconhecendo-se as sim, o período de tempo decorrido após a infecção.

A utilizaçāo da amostra Patoc I para o diagnóstí co sorológico da leptospirose em cães forneceu resultados con traditórios de acordo com os autores que se dedicam ao assunto, $28,32,43$, sugerindo-se entretanto que, uma boa concordância entre os resultados da soroaglutinação utilizando antígenos re presentados por leptospiras patogênicas e os obtidos com 0 uso de linhagens saprófitas indicaria infecçōes recentes e a ausên cia desta concordância indicaria infecção antiga ${ }^{32}$ : 0 emprego 
de outras cepas de leptospiras aquícolas com a mesma finalidade tem tambëm fornecido resultados controversos, considerados bons por uns 9,10 , e contestados por outros ${ }^{43}$. Deve-se ressaltar todavia que na maioria das vêzes, a interpretação dos resulta dos não tem sido. suficientemente clara por se desconhecer as informaçōes relativas ao estágio da doença ou o período de tem po decorrido após a infecção.

A reação de fixaçāo de complemento é uma reação mais laboriosa do que a reação de aglutinação microscópica, mas parece ser mais especifica para revelar infecções recentes,pois os anticorpos fixadores de complemento são observados mais pre cocemente, desaparecendo da circulação sanguínea em um curto pe ríodo de tempo que, segundo alguns autores 23,24 , gira em tor no de 60 a 90 dias. Ao contrário, os anticorpos aglutinantes podem ser observados na circulação por um período longo de tem po; persistindo às vêzes durante toda a vida do animal ${ }^{4}$. As sim, reaçōes de microaglutinação positiva, principalmente em baixos titulos, podem indicar infecção recente en evolução ou uma infecção mais antiga, não permitindo desta forma, estabele cer o diagnóstico de infecção ativa ${ }^{50}$.

Para os profissionais é de grande interesse ter informaçōes mais precisas em relação ao estágio da infecção ou da doença, fato que lhes daria melhores possibilidades de tra tar o animal com sucesso, evitando que o paciente se torne um portador, com risco de contaminação do meio ambiente. 0 conhe cimento da dinâmica da evoluçāo dos anticorpos em cães recente mente infectados e a possibilidade do emprego de um antígeno $\underline{\underline{u}}$ nico poderiam trazer subsidios para o diagnóstico precoce da leptospirose, minimizando o risco de infecção humana pelo con tacto com esses animais.

o presente trabalho tem como propósito acompanhar a dinâmica da evolução dos anticorpos durante as primeiras se manas de infeç̧ão em animais experimentalmente infectados com os sorotipos icterohaemorrhagiae e canicola. Para tanto, serão 
utilizadas as reaçōes de aglutinação microscópica e fixạāo de complemento, realizando-se um estudo comparativo entre ambas e avaliando-se também a verdadeira potencialidade do uso das es tirpes aquicolas Patoc I, Rufino e Buenos Aires como antígeno únilo nas citadas reações. 
2. LITERATURA.

A partir de 1917, quando o gênero Leptospira foi criado por NOGUCHI, sua sistemática tem sofrido inúmeras modifi cações, aceitando-se porém como bactérias da ordem Spirochaeta les, familia Spirochaetaceae, gênero Leptospira 5 . Em 1962, o subcomitê taxonônico para o estudo do gênero ${ }^{52}$ concordou com uma subdivisão em duas espécies: Leptospira biflexa, represen tando as saprófitas ou aquícolas, encontradas em coleções líqui das, terrenos lamacentos e mesmo na āgua potävel e; a Leptospi ra interrogans ou icterohaemorrhagiae, englobando as formas pa rasitárias, isoladas de animais e do homem. A diferenciação das espécies foi baseada na capacidade de infectar animais, resis tência aos ions cobre bivalentes, características imunológicas e crescimento em meio de cultura livre de soro animal. A estes, foram anexados outros critérios, tais como a resistência a 8 -azaguanina ao verde malaquita e à fucsina básica, atividade $1 \underline{i}$ politica, a reação de oxidase, tolerância ao cloreto de sódio e à temperatura e habilidade en provocar efeito citopático em cul turas de células 32 .

Estudos realizados com leptospiras isoladas do homem e de animais vieram revelar entretanto, que, muitas amos tras tendiam a se enquadrar na espécie biflexa. Em virtude de tais fatos, o Grupo de Peritos em leptospirose, da Organização Mundial de Saúde 33 , passou a recomendar que fosse considerada apenas uma espécie no gênero Leptospira até que houvesse pos sibilidade de diferenciar perfeitamente as espécies, recomendan do também a utilizaçāo do termo interrogans, mais apropriado do que icterohaemorrhagiae ou biflexa. Passou-se também a utili zar o termo "complexo interrogans", englobando os dois grupos de leptospiras jā referidos e compostos por amostras sorologica mente distintas. Dentro deste complexo estão os sorogrupos, constituídos por una reunião de sorotipos, tendo como base suas relações antigênicas. Atualmente são considerados 18 sorogru pos com aproximadamente 150 sorotipos, dentro do gênero Leptos pira. O sorotipo é definido como a unidade taxonômica básica. 
A aglutinação de uma suspensão de leptospiras pe 10 soro de pacientes com a moléstia de Weil foi observada nos primórdios do século e a partir dessas observaçōes, MARTIN \& PE TIT 29 desenvolveram em 1918 um método de aglutinação que, em linha gerais, serviu de base para a reação de aglutinação mi croscôpica recomendada pela Organização Mundia de Saúde 33 , señ do largamente utilizada em todo o mundo para fins de diagnóstí cos e para a realização de inquéritos epidemiológicos.

A reação de fixação de complemento para o diag nóstico da leptospirose humana foi descrita inicialnente por BESSEMANS \& NELIS ${ }^{6}$ (1928), utilizando como antígeno uma suspen são de leptospiras do sorotipo icterohaemorrhagiae. A partir da padronização desta tếcnica, o preparo dos antígenos sofreu inū meras modificaçōes, desde as mais simples até as mais complica das, como por exemp10, os antigenos inativados qumicamente ou pelo calor, extraídos pelo álcool ou ainda, sonicados. ${ }^{50}$.

Alguns dos antígenos preparados com amostras pa togênicas apresentam alta especificidade, reagindo apenas con os anticorpos homölogos, enquanto outros apresentam reações cru zadas com anticorpos heterölogos, sendo portanto considerados. gênero - especificos 41. Diversos pesquisadores procuraram au mentar o espectro de ação, possibilitando assim o encontro de maior nümero de reagentes para os diferentes sorotipos, através da utilização de um "pool" de antígenos $7,41,21$.

De um modo geral, observou-se concordância de 80 a 100 entre os resultados obtidos nas reações de aglutinação microscōpica e fixação do complemento pelo emprego de antígenos preparados con uma mesma amostra de leptospira patogênica em soros humanos $39,50,21,38$, bovinos 36,41 , suínos 23 e cani nos 34 .

o conhecimento de que antígenos preparados a par tir de certas linhagens aquícolas de leptospiras são às vëzes aglutinadas pelos soros de individuos infectados por sorotipos natogênicos de Leptospira induziu muitos pesquisadores a procu 
rarem, entre as diversas cepas apatogênicas uma amostra que apre sentasse una reação cruzada com a maioria dos sorotipos patogê nicos. KMETY ${ }^{25}$ (1958), observou que leptospiras da estirpe Pa toc I eram frequentemente aglutinadas en altas diluiçōes pelo soro de pacientes con loptospirose, algunas vêzes mais precoce mente do que quando se utilizava antígenos produzidos com 0 so rotipo patogênico responsãvel pela doença.

A primeira tentativa real de utilizaçāo de lep tospiras aquícolas no diagnōstico da leptospirose foi feita por cox e col., 16 (1958). Bstes autores extrairam de una cepa apa togênica un antígeno solúvel, capaz de sensibilizar hemácias do carneiro, as quais eran lisadas quando testadas com complemento e soro humano contendo anticorpos para leptospiras patogênicas. Embora tivessen obtido bons resultados con soros humanos posit 1 vos, a reação fol considerada pouco prätica para fins diagnŏst1 cos.

A partir dessas observaçōes, outros pesquisado res procuraran testar diversas estirpes de leptospiras aquíco las, através das reaçōes de fixação de complemento e aglutina çāo microscôpica.

$$
\text { COMBIESCO e col., } 13 \text { (1958), em um estudo epide }
$$
miolögico da leptospirose humana abrangendo os anos de 1950 a 1957, haviam observado que, leptospiras da cepa Patoc I eram a glutinadas en elevadas proporcōes pelo soro de pacientes com leptospirose. Prepararam entảo, um antígeno concentrado da mes ma amostra, para ser empregado na reação de fixação do comple mento. Em uma série de estudos subsequentes, pesquisadores do mesmo grupo rumeno 45,46 conseguiram demonstrar que os resulta dos da fixaçāo do complemento com esse antígeno coincidem em aproximadamente 909 dos casos com os do teste de aglutinação in croscóplca empregando-se antigenos homólogos. Observaram tam bém que os testes gênero - específicos tornam-se negativos após 2 a 6 meses, prestando-se para o diagnístico dos casos recentes de leptospirose humana. A especiflcidade e sensibilidade da ce pa Patoc 1 foram maiorps do que as das outras cepas nạo patogê nicas c omo Madida, Velurat Semarang 173 , Peschiera e Ancona 46. 
ADDAMIANO ${ }^{1}$ (1962) também procurou empregar o an tígeno Patoc I no diagnóstico da leptospirose pela reaçāo de a glutinaçāo microscópica, observando que a sensibilidade e a es pecificidade eram altas o suficiente para recomendá-1o como an tígeno de triagen nos casos suspeitos de leptospirose. Em 1968. ADDAMIANO \& BABUDIERI ${ }^{2}$ analisaram o comportamento das estirpes Patoc I e São Paulo nas reacōes de aglutinação microscópica e de fixação de complemento, obtendo uma sensibilidade de 74,48 e 818 respectivamente, con o antigeno Patoc I, nos casos positi vos de leptospirose humana por diferentes sorotipos de leptospi ras patogênicas. 0 antígeno produzido com a cepa São Paulo a presentou atividade ligeiramente inferior.

Os resultados obtidos por FUCHS ${ }^{18}$ (1968) pelo en prego da cepa Patoc I foram parcialmente discordantes pois obser vou una concordancia de-apenas 59.78 em casos positivos de lep tospirose causada por diversos sorotipos de leptospiras patogê nicas e de 96.88 quando se tratava especificamente de infecçōes determinadas pelos sorotipos icterohaemorrhagiae e canicola. Re sultados semelhantes foran obtidos por HERGT ${ }^{22}(1976)$, que, pes quisando a sensibilidade e especificidade do antígeno Patoc I, na reação de aglutinação microscópica observou haver concordân cia de $50 s$ entre os resultados assim obtidos e os encontrados com o emprego de sorotipos patogênicos. Mesmo assim, sugeriu a necessidade da inclusão dessa estirpe aquícola na bateria de an tígenos utilizados no diagnóstico sorológico da leptospirose., pois permitiria revelar os reagentes de forma mais precoce do que os antígenos de emostras patogênicas.

Anticorpos aglutinantes para leptospiras aquico las também foran observados no soro de diversas espécies an mais. Segundo ADDANINNO \& BABUDIERI ${ }^{2}$ (1968), essas observaçōes foran feltas en soros de cobaios inoculados com o sorotipo icte rohaemorrhagiae que aglutinavan a estirpe Vinzenti; en soros de cavalos, cães, ratos cobaios que reagiam com as estirpes To kio, Erlangen e Vinzenti; e en soros de frangos que apresenta vam aglutininas para o sorotipo andamana. 
Cox - ed.. ${ }^{16}$ (1958) procuraran testar o antfoe no extraído da lithage coe de leptespira aquícóna, coil soros de bovinos equinos positínes para leptospiras patogênicas, com a finalidade de avaliaz poteneialidade do seu emprego para fins disgnósticos da leptospltrose enimal, nắo tendo obtido porếin, rę sultados satisfatöfios como ocorteu col os soros humanos. COM BIEsco e co1., 13 (1950) tablet obtiverain resuitados quase nulos

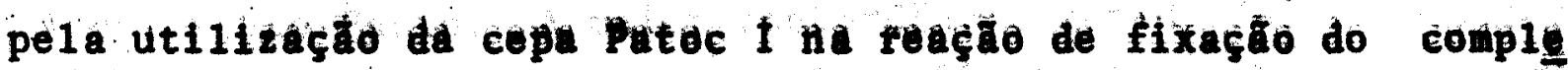
mento com sotos bovinos equinos, enquanto observavai positivi dade da order te 85.71 ed os soros hiperimunes de coethos para diversos sorotipos de leptospliras patogenicas.

\section{NICOLBSCO LELUTtU ${ }^{32}$ (1967), na tentativa uti} lizar um antigeno tinito ht teaço de fixaçáo do complemento coî a finalidado do dotectat a loptospitose nos anilud is domếsticos, prepararail uil antifeno concentrato coll a cepa Patoc I, testento-6 con soros de 1eporitios, cthifies, sufhos, bovinos e equitios posi tivos na prova to afutinuglo wicrosebpica rea1izada coil antige nos preparados con sorotipos patogênicos. Os resultados obti dos foram pouco conelusivos, pois as 42 anostras de caes rea gentes a sorotipo enticeil. 401 fornecerain resultados positi

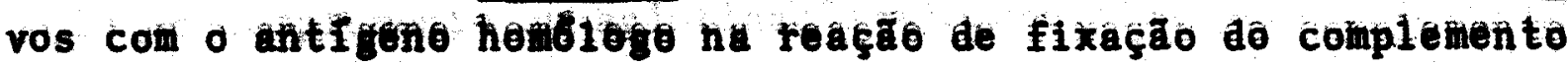
668 com o antigeno Patoe 1 e 91 con o antígeno săo Paulo. Veri ficaran tabbin que, os tesultedos train diferentes conforme o 10 te de animais estudados, stgerindo assin que uñ boa concordân cia entre os tesultados da sorodglutinaçäo microscấpić con lę tospiras patogônieds - os obtidos coll o emprego de linhàgens sa

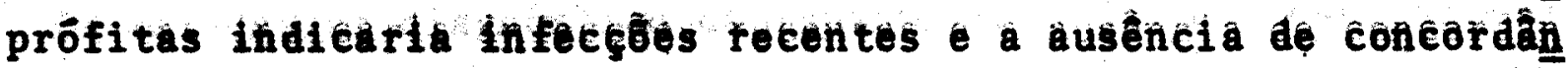
cia, infecçő̀es untigas.

J6 Whblouk 28 (1967), obteve resultades bastan

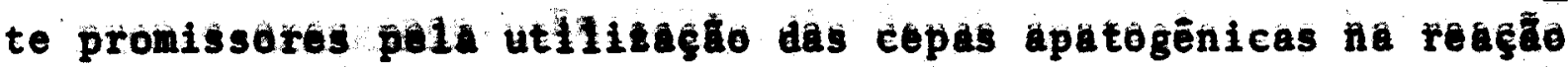

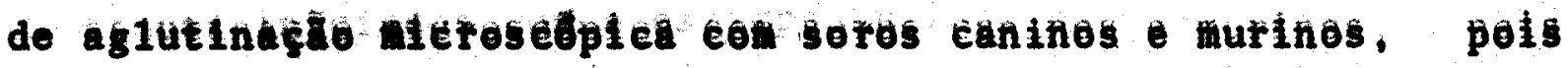
observou que, on 9,81 des easos, havia concerdância entre os re suitados dos testes do allutitiaglo mierosedpica com leptospiras

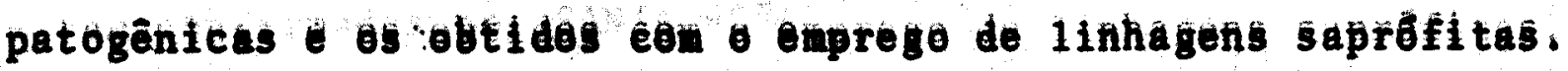
Ainda, segindo 0 meswo tuter, soros hiperimunes preparados cen leptospiras patogentés aglutinavain as amostras saprofitas. P鲜 
toc I, São Paulo - Saada, enquanto imune-soros das duas - prime 1 ras estirpes aquícolas, aglutinavam leptospiras pertencentes a 12 diferentes sorotipos patogênicos.

Pata ADANINNO BABUDIERI 2 (1968), os resulta dos foram pouco satisfatórios con soros de bovinos, equinos, suí nos, ovinos, caninos - leporinos utilizando-se as estirpes Pa toc I e São Paulo. A maior concordância obtida foi de 68.88 en tre os soros de equinos e a estirpe São Paulo. Por outro 1ado, observaram também que, muitos soros negativos aglutinavam lep tospiras da estirpe Patoc I.

PETELIN e col., 37 (1970), estudando várias es tirpes de leptospiras saprófitas visando ao diagnóstico da led tospirose humana, incluiram en seu trabalho soros de animais positivos para leptospiras, concluindo que, a proporção de resul tados positivos era auito pequena para se aconselhar a prova com tais antigonos no diagnóstico da leptospirose animal.

A inconstância dos resultados obtidos pelo empre go da estirpe Patoc I cono antígeno único nas reaçōes de fixa ção do complemento ou aglutinação microscópica para o diagnósti co da leptospirose animal, estimulou outros pesquisadores a tes tarem diferentes copas de leptospiras aquicolas. Assim,CACCHIO NE - col., 9 (1971) utilizaram várias cepas de leptospiras aquí colas isoladas na Argentina - verificaram que a estirpe Rufino apresentava reaçōes cruzadas com värios sorotipos patogênicos. Em relação ao diagnóstico da leptospirose canina resultadosreal mente promissores foran obtidos por esses autores, pois obser varam uma concordância do 1001 nas infecçōes determinadas pelos sorotipos icteroheenorrhagise, canicola, ballum, bratislava, bu tembo e prrorenes. Bn 1972, CACCHIONE e col., 10 ampliaram os estudos iniciados con estirpe Rufino, obtendo resultados sene lhantes com os soros de cảes reagentes para outros sorotipos de leptospiras patogônicas. Entretanto, esses resultados não fo ram confirmados por SANTA ROSA 43 (1977), pois este autor verí ficou que, polo emprego dos antígenos Patoc I e Rufino na reaçäo. de aglutinação nicroscóplca, os resultados eram praticamente ne 
gativos com os soros de bovinos, suinos e caninos positivos pa ra luptospiras patogênicas. Esse mesmo autor preconizou o en prego da estirpe Buenos Aires no diagnóstico da leptospirose a nimal, pois obteve uma proporção de 77,58 de reaçōes positivas com os soros de cães reagentes ao sorotipo icterohaemorrhagiae de 808 no caso de cães positivos ao sorotipo canicola. Nos ou tros espécimes considerados, a sensibilidade dessa estirpe aquí cola foi próxima a 1001 . 
3. MAIERIAL E METODOS:

\subsection{Inoculacão exper1mental.}

\subsubsection{Selecão dos animais.}

Foram utilizados 30 animais da espécie ca nina, adultos, sem raça definida e considerados sadios. Os animais foram previamente imunizados contra cinomose e hepatite - receberam tratanan to antihelmintico (mebendazole na dose de 20mg/ $/ \mathrm{kg} / \mathrm{dia}$, durante 3 dias). Antes de serem inclui dos no experimento procedeu-se ao exame clínico, hematolögico o de urina de cada animal, ben cono à pesquisa de anticorpos antileptospiras pela técnica de soroaglutinação microscópica,utilizan do-se como antigenos os sorotipos representati vos de 18 sorogrupos patogénicos do complexo Lep tospira interrogans e os 3 sorotipos de loptos piras aquicolas a serem estudados no presente ex perimento (TABELA 1). Procurou-se ainda, inves tigar o estado de portador renal através da cul tura de urina en meio de Fletcher.

Foram incluidos nos 2 lotes experimentais apenas os animais que se apresentavam clinicamen te notmais, sem alteraçōes no exame hematológico - de urina. livres de anticorpos contra qualquer um dos antígenos empregados $\bullet$ que não se caracte rizavam como portadores renais.

3.1.2. Inōculo.

As amostras dos sorotipos icterohaemortha giae canicola utilizades no inoculação dos cies provieram do Departamento de Microbiologia Inu nologia do Instituto de Ciôncias Biomédicas da 
Universidade de São Paulo" e haviam sido recen temente isoladas de rim de un rato de esgoto (a mostra $R$ 10) - de un cão de rua (amostra CCZ 8). Culturas de 15 a 20 dias en moio semi-sōlido fo ram inicidmente inoculadas en cobaios jovens por via intraperitonial, reisolando-se desta maneira as leptospiras do rin 21 dias após e a segulr. novamente inoculadas en outros cobaios. Após a 2a. passagem, as leptospiras foram cultivadas du rante 5 dias a $28^{\circ} \mathrm{C}$ en meio líquido (ENH - Dif co), enriquecido de soro de coelho a 108 e use das como inóculo.

\subsubsection{Constituicäo dos grupos.}

0 grupo I foi composto de 15 animais dos quais 14 eram machos e 1 fômea, previamente sele cionados o preparados da forma anteriormente ci tada. Cada animal foi inoculado $\operatorname{com} 2,0 \mathrm{ml}$ da cultura de 5 dias da amostra $R 10$ do sorotipo ic terohaemorthagiae, (aproximadamente $2 \times 10^{9}$ lep tospiras), por via sub-cutânea.

- grupo II foi tambén constituído por 15 animais, sendo 12 machos o 3 fêmeas,selecionados - preparados de imaneira idéntica aos animais do 10 grupo e inoculados com $2,0 \mathrm{ml}$ da cultura de 5 dias da amostra CCZ 8 do sorotipo canicola, (a proximadamente $2 \times 10^{9}$ leptospiras), também por via sub-cutânea.

Apös a inoculaçāo, os animais foram con trolados diariamente durante os primeiros 14 dias, observando-se as alteraçōes clínicas, dando-se destaque às variaçōes da temperatura retal. Após esse período de tempo, o exame clínico do ani mal foi realizado en intervalos semanais.

* Gentilmente cedidas pelo Dr. Paulo Hideki Yassuda. 
Decorridos 56 dias para o $1^{9}$ grupo .63 dias para $\circ 2^{\circ}$ grupo, todos os animais sobrevi ventes foram sacrificados, observando-se as alte raçōes macrọscópicas e microscópicas dos rins,fí gado e pulmão. Um fragmento do rim de todos os animais foi coletado asseticamente, por meio de uma pipeta Pasteur e cultivado em meio de Flet cher adicionado de 108 de soro de coelho, para isolamento de leptospiras.

3.1.4. Coleta de sangue e de urina.

Amostras de sangue para os exames hemato lógicos e sorológicos foram coletadas das veias periféricas (safena, radial ou jugular), proceden do-se antes aos devidos cuidados de assepsia,ime diatamente antes da inoculação e decorridos 4,7, $10,14,21,28,25,42,49,56$ e 63 dias.

A amostra que se destinava ao exame hema tolögico foi coletada em frascos contendo EDTA (sal de aćido etileno diamino tetracétíco) como anticoagulante e-o restante do sangue foi coloca do óm tubos de vidro umedecidos com salina fisio lógica. Após a retração do coágulo, a amostra foi centrifugada a $1.500 \mathrm{rpm}$ durante 15 minutos, separando-se a seguir o soro que, foi mantido a $-4^{\circ} \mathrm{C}$ até o momento do seu uso.

- As amostras de urina foram coletadas atra vés de cateterismo vesical utilizando-se sondas descartáveis munidas de coletores para os machos - sondas metálicas esterilizadas para as fêmeas. Imediatamente após a coleta, foram semeadas $3 \mathrm{~g} \underline{\underline{0}}$ tas de urina pura, diluída a $1: 10,1: 100$ e $1: 1000$ com solução salina fisiológica em meio de Fletcher. - qual foi mantido a $28^{\circ} \mathrm{C}$ durante 30 dias. 
TABELA 1 - Antígenos utilizados na reação de soroaglutinação microscōpi ca para a seleção dos animais experimentais. São Paulo, 1979 .

\begin{tabular}{|c|c|c|}
\hline Antigeno & Sorotipos & Cepa \\
\hline 1 & icterohaemorrhagiae & RGA \\
\hline 2 & canicola & Hond Utrecht IV \\
\hline 3 & pomona & Pomona \\
\hline 4 & grippotyphosa & Moskva V \\
\hline 5 & tarassovi & Perepelicin \\
\hline 6 & australis & Ba11ico \\
\hline 7 & bataviae & Van Tienen \\
\hline 8 & castellonis & Castellón 3 \\
\hline 9 & wolffi & 3705 \\
\hline 10 & panama & $\mathrm{CZ} 214 \mathrm{~K}$ \\
\hline 11 & pyrogenes & Salinem \\
\hline 12 & javanica & Veldrat Bat. 46 \\
\hline 13 & autumnalis & Akiyami A \\
\hline 14 & butembo & Butembo \\
\hline 15 & andamana & $\mathrm{CH} 11$ \\
\hline 16 & whitcombi & Whitcomb \\
\hline 17 & shermani & Lt 821 \\
\hline 18 & brasiliensis & An 776 \\
\hline 19 & patoc & Patoc I \\
\hline 20 & - & Rufino \\
\hline 21 & - & Buenos Aires \\
\hline
\end{tabular}




\subsection{Reação de soroaglutinaçāo microscópica.}

3.2.1. Antigenos".

Os antigenos empregados na reação de soroaglu tinação microscópica para a seleçāo dos animais expe rimentais, em número de 21 ,estão relacionados na TABELA 1. O meio de cultura empregado para o prepa ro dos antígenos foi EMJH (DifCo), onde se acrescen tou 108 de soro de coelho livre de anticorpos antileptos piras - proviamente inativado a $56^{\circ} \mathrm{C}$ durante $45 \mathrm{mi}$ nutos. Cada tubo contendo o meio foi semeado com a amostra, na proporção de 10 \& e incubado a temperatú $r a$ de $28^{\circ} \mathrm{C}$ durante 6 dias. Antes de serem usados, eram examinados quanto a sua pureza, densidade, presença de autoaglutinação e densidadé microbiana. Os antí genos foram considerados adequados quando se apresen tavam livres de contaminação, de autoaglutinação e com densidade correspondente a 100 leptospiras por campo microscópico no exame em microscopia de campo escuro, usando-se um aumento de $450 x$.

Nas reaçōes de aglutinaçāo microscōpica com as amostras de soro coletadas após a inoculação fó ram utilizados os antígenos homólogos icterohaemorrhagiae, para $01^{\circ}$ grupo de animais, e canicola para os animais do $2^{\circ}$ grupo e os antígenos prepa rados com as amostras das estirpes aquícolas patoc I Rufino e Buenos Aires. .

\subsubsection{Técnica da soroaglutinação microscópica.}

Os soros foram inicialmente diluídos a $1: 50$ em solução fisiológica com tampão de Sberensen, de acordo com SANTA ROSA ${ }^{42}(1970)$. Desta diluição, alí

- Pertencentes à coleção do Prof:Dr. Carlos Almeida Santa Rosa, do Departamen to de Modicina Veterinária Preventiva e Saúde Animal da Faculdade de Medicí na Veterinária e Zootecnia da USP, e gentilmente cedidos pelo mesmo. 
quotas de $0,2 \mathrm{ml}$ foram distribuídas em 21 tubos de ensaio, adicionando-se a seguir $0,2 \mathrm{ml}$ de cada um dos antígenos na bateria de tubos correspondentes a uma amostra sérica, obtendo-se assim, uma diluição final de $1: 100$.

Os tubos com a mistura soro-antígeno eram le vemente agitados 0 incubados em estufa a $28^{\circ} \mathrm{C}$ du rante trôs horas, para a seguir, proceder-se a le tura, usando-se microscopía de campo escuro com au mento de $150 \mathrm{x}$. Uma gota da mistura soro-antígeno ora colocada sobre uma lâmina de vidro e levada ao microscópio, observando-se a existência ou nāo de aglutinação.

O grau de aglutinação era lido e avaliado de acor do com o seguinte critério: 1+ quando pelo menos 25 i das leptospiras estavam aglutinadas no campo microscópico; $2+$ quando havia 508 de aglutinaçäo; 3+ e 4+ quando se observaven a aglutinação de respectivamente 75 - 100 das leptospiras.

Foram consideradas positivas as reações em que houve aglutinação de pelo menos 508 das leptos piras.

As amostras de soro coletadas após a inoculação foram diluídas com salina fisiológica com tampão de Sberensen, a. $1: 50,1: 100,1: 200,1: 400,1: 800,1: 1600$, $1: 3200$ e $1: 6400 ; 0,2 \mathrm{~m} 1$ destas diluiçōes foram dis tribuidas em 4 tubos de ensaio, adicionando-se a seguir $0,2 \mathrm{ml}$ dos antígenos e procedendo-se da ma neira idêntica à citada anteriormente.

O título de cada soro foi considerado o in verso da diluiçào en que pelo menos 508 das lpptos piras se encontravam aglutinadas. 


\subsection{Reaçāo de fixação do complemento.}

\subsubsection{Hemácias de carneiro.}

Durante tôdas a investigação foram usadas hemácias de carneiro conservadas em solução de Alsever modificada de acordo com BUKANTZ e col. 8 (1946)". No momento do uso, as hemácias foram filtradas on algodão hidrófilo e a seguir lava das 3 vêzes por centrifugação a $1.500 \mathrm{rpm}$, duran te 10 minutos em solução fisiológica. Da papa de hemácias obtida após a 3a. centrifugação, pre parou-se uma suspensão a 5 em solução fisiológi ca, padronizando-a a seguir para densidade ótica 0,56 em espectrofotômetro Colleman $\mathrm{Jr}$., mode10 6A em comprimento de onda de $545 \mathrm{~nm}$.

\subsubsection{Hemolisina anti-hemácias de carneiro.}

A hemolisina foi preparada em coelhos, se gundo a técnica descrita por ULRICH \& MAC ARTHUR $51(1942)$ "e foi usada na sua concentração ótima de $1: 1000$.

\subsubsection{Complemento.}

Como fonte de complemento utilizou-se uma mistura de soros de 20 cobaios machos, distribuí da en aliquotas de 1 a $2 \mathrm{ml}$, que foram conserva das à temperatura de $-20^{\circ} \mathrm{C}$ até o momento do uso. 0 complemento foi titulado en unidade 508 de he mólise, de acordo com a técnica descrita por CA MARGO - col., 11 (1950), cada vez que se procedia à realização da prova de fixaçāo do complemento.

- Preparadas e gentilmente cedidas pelo Prof.Dr. Aramis A.Pinto, do Departamenţo de Microblologia e Imunologia do Instituto de Ciôncias Biomódicas da USP.- 


\subsubsection{Antígenos.}

Os antígenos utilizados na reação de fixa ção do complemento foram preparados de acordo com a técnica descrita por STURDZA e col., 45 (1960) com ligeiras modificações. Para o preparo do an tígeno foram usadas as seguintes cepas de leptos piras: Leptospira interrogans sorotipo canicola estirpe Hond Utrech IV, sorotipo icterohaemorrha giae cepa R.G.A. e as cepas Rufino, Buenos Aires e Patoc I das leptospiras aquícolas. As amostras foram semeadas em meio líquido (EMJH - Difco) a crescido de 108 de soro de coelho e incubadas a $28^{\circ} \mathrm{C}$ durante 8 a 10 dias. Havendo um bom cres cimento, as culturas foram centrifugadas a 10.000 rpm durante 30 minutos em centrífuga refrigerada a $4{ }^{\circ} \mathrm{C}$. O sedimento obtido foi ressuspenso na proporção de $1: 10$ do volume original em solução fisiológica contendo mertiolate a $1: 10.000$. As suspensões dos antígenos assim preparadas foram conservadas à temperatura de $4{ }^{\circ} \mathrm{C}$ até 0 momento do uso, tendo sido agitadas ocasionalmente duran te os primeiros dias. Durante todo o experimen to os antígenos foram utilizados em sua dose de reatividade ótima. Para tanto, realizou-se a ti tulação em bloco, em que várias diluiçōes do an tígeno foram testadas contra vārias diluiçōes dos respectivos soros hiperimunes, empregando-se 2,5 unidades de complemento ( 50 q hemölise).

\subsubsection{Soros hiperimunes.}

Para obtenção dos soros hiperimunes, coe 1hos adultos normais de aproximadamente $2.500 \mathrm{gra}$ mas de peso foram inoculados por via endovenosa, na veia marginal da orelha. Foram praticadas 5 inoculações de culturas vivas de leptospiras em meio líquido, em doses sucessivas de $1,2,4,4$, 
$4 \mathrm{ml}$, com intervalos de 6 dias entre càda ino culação. Decorridos 6 dias após a última inocu lação procedeu-se a sangria branca; os soros ob tidos foram titulados pela técnica de aglutina ção microscópica com o antígeno homólogo. Os tí tulos obtidos para todos os soros variaram de 51.200 a 102.400 .

Os soros hiperimunes foram usados para ti tular os antígenos empregados nas provas de fixa ção do complemento, e também como controle pos $\underline{i}$ tivo nas reaçōes de aglutinação microscópica.

\subsubsection{Soros.}

Os soros a serem testados foram coletados de animais infectados experimentalmente com as leptospiras dos sorotipos icterohaemorrhagiae e canicola conforme o item 3.1.4. Cada amostra de soro foi diluída em soluçāo fisiológica a 1:5,1:10, e assim sucessivamente até a diluição 1:640, e testada contra o antígeno homólogo e contra os antígenos heterólogos Buenos Aires, Patoc I e Ru fino.

\subsubsection{Técnica da reação de fixação do complemento.}

Para as reaçōes de fixação do complemento utilizou-se a técnica descrita por CAMARGO e col. 11 (1950) utilizada rotinciramente no sistema fe bre aftosa, sendo os seguintes os volumes dos reagentes e o tempo de incubação:

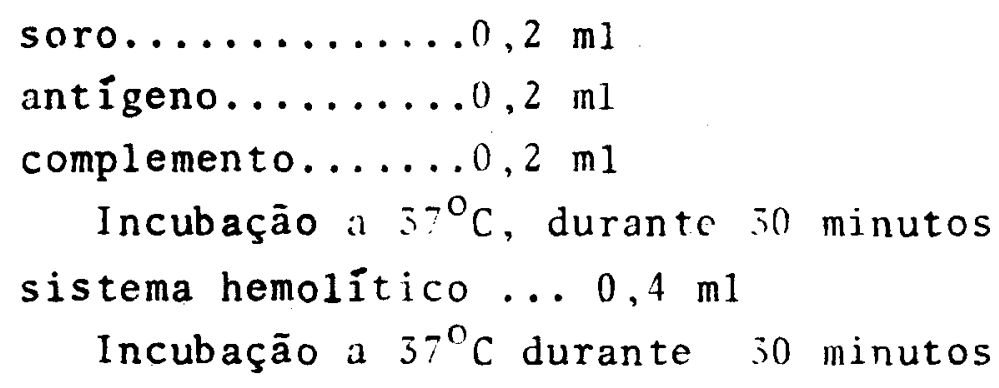


Após o período de incubação, cada tubo foi centrifugado, fazendo-se a leitura da densidade ótica do sobrenadante em espectrofotômetro $\mathrm{Co} 1$ lemann $\mathrm{Jr}$. modelo $6 \mathrm{~A}$, em comprimento de onda de $545 \mathrm{~nm}$. A partir da densidade ótica calculou-se a percentagem de hemölise. As reaçōes foram con sideradas positivas quando não houve hemólise, cal culando-se o título final do soro nas diluições em que se observou 508 de hemölise ou empregando -se a seguinte expressão, em substituição ao mé todo da leitura em gráfico estabelecido pela téc nica de CAMARGO e col., 11 (1950):

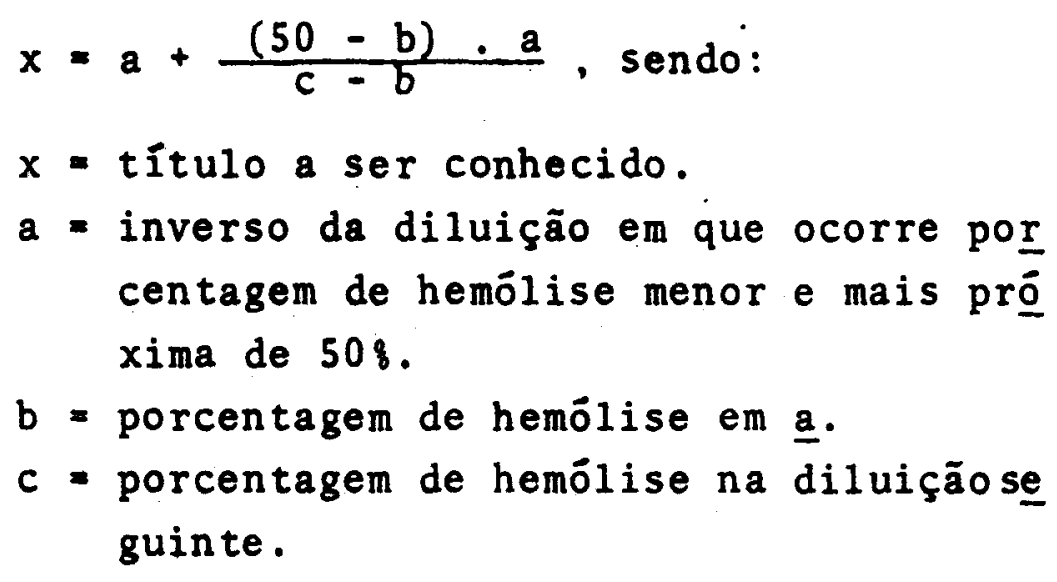
centagem de hemólise menor e mais pró xima de 508 .

$\mathrm{b}=$ porcentagem de hemólise em $\underline{\mathrm{a}}$.

c = porcentagem de hemölise na diluiçãose guinte. 
4. RESULTADOS.

4.1. Reação de soroaglutinação microscópica e de fixação do complemento frente aos antígenos homólogos.

Todos os animais inoculados com leptospiras pa togênicas dos sorotipos icterohaemorrhagiae ou canicola responderam ao estímulo antigênico, produzindo anticor pos fixadores do complemento e aglutininas detectados na circulaçāo sanguínea através das reações de fixaçāo do complemonto e de soroaglutinação microscôpica. No $4^{\circ}$ dia após a inoculaçāo, 7 dos animais infectados pelo soroti po icterohaemorrhagiae (478) e 8 dos animais inoculados con o sorotipo canicola (538) foram reagentes à reação de fixaçāo do complemento, frente aos antígenos homōlo gos, enquanto näo se observou nenhum resultado positivo na reação de aglutinaçāo microscópica.Jā no 79 dia, 878 dos cāes do grupo I, e 1008 dos animais do grupo II, a presentaram anticorpos fixadores do complemento. Nessa ocasião as aglutininas foram detectadas em títulos 100 em 803 dos cāes do $1^{\circ}$ grupo e em 538 dos cães do $2^{\circ}$ grú po. Ambas as reaçōes tornaram-se positivas em todos os animais infectados pelo.sorotipo icterohaemorrhagiae - pelo sorotipo canicola, 10 dias após a inoculação (TA BELAS 2 e 3).

Quando se compara a evoluçāo dos anticorpos re velados pelas duas reaçōes empregadas no presente expé rimento, pode-se observar que a persistência dos antí corpos fixadores do complemento foi por um periodo me nor de tempo, desaparecendo totalmente da circulação sanguínea 56 dias após a inoculação com o sorotipo icterohaemorrhagiae e 63 dias após a infecção pelo soro tipo canicola (FIGURAS 1 e 2 ).

De um modo geral, a ascenção dos títulos para as reaçōes de fixaçāo do complemento e de aglutinaçāo mi croscópica é răpida, enquanto o declínio é mais lento. 
Os anticorpos aglutinantes tendem a persistir na circu laçāo por um período maior de tempo, embora em títulos baixos (TABELAS 4;5,6 e 7). Existe uma variação mui to grande no nível sérico de anticorpos humorais detec tados por ambas as reações, encontrando-se título máxí mo de 6.400 para a reação de soroaglutinação microscópí ca e $\geqslant 640$ para a reaçāo de fixaçāo do complemento.

\subsection{Reações de soroaglutinação microscópica e fixação do com plemento frente aos antígenos heterólogos.}

\subsubsection{Estirpe Patoc I.}

Oi to dos 15 animais (538) inoculados com o so rotipo icterohaemorrhagiae apresentaram reação de aglutinação microscópica positiva quando se uti lizou como antígeno a suspensāo de leptospirasda estirpe aquícola Patoc I, embora por um período curto de tempo, abrangendo do $7^{\circ}$ ao $21^{\circ}$ dia (TA BELA 8). Desses oito reagentes dois não apresen sentaram anticorpos capazes de fixar o complemen to na presença de antígeno Patoc I. O período de persistência desses anticorpos na circulação pe riférica é bastante curto, pois, en 2 animais, a reação foi positiva em apenas uma amostra sērica, enquanto en outros, observou-se reação positiva em 2 ou 3 amostras séricas consecutivas.

Menor positividade foi obtida no grupo de ani mais inoculados com o sorotipo canicola, no qual se observaram apenas 5 reagentes no teste de a glutinaçāo microscōpica e 4 no teste de fixação do complemento, correspondendo a uma proporção, respectivamente de 33 e 278 (TABELA 9).

Os títulos das reaçōes de aglutinação micros cópica com o antígeno Patoc I não excederam o título mínimo considerado significativo (100) em 
ambos os grupos de animais. Os títulos observa dos nas reaçōes de fixação do complemento tambén foram baixos variando entre 5 e 30 .

\subsubsection{Estirpe Rufino.}

Entre os animais do grupo I, inoculados com 0 sorotipo icterohaemorrhagiee, 7 animais (538) a presentaran reação de soroaglutinaçāopositiva du rante um curto período de tempo quando se utili zou como antigeno a suspensio de leptospiras a quícolas da amostra Rufino, não se observando ne nhum reagente 28 dias apōs a inoculação (TABELA 10).

Pela reação de fixação do complemento, quando se testaram os mesmos soros frente ao antígeno preparado com a estirpe Rufino, não se obteve ne nhum resultado positivo.

Caracteristicas semelhantes foram observadas entre os animais inoculados com o sorotipo cani cola pois, na reaçāo de fixaçāo do complemento nāo se observou nenhuma reação positiva frente ao an tígeno Rufino, enquanto foram observados 8 (53i) reagentes pela reação de aglutinaçāo microscópica (TABELA 11).

Os títulos medidos pela reação de aglutinação microscópica foram baixos, como havia sido obser vado quando se utilizou a estirpe Patoc I.

\subsubsection{Estirpe Buenos Aires.}

Dos animais inoculados com o sorotipo ictero haemorrhagiae, $87 \%$ apresentaram reação positiva aos testes de fixaçāo do complemento e aglutina ção microscópica, frente aos antígenos prepara 
dos com leptospiras da estirpe Buenos Aires. En tre os animais fo grupo II, inoculados com lep tospiras patogônicas do sorotipo canicola, a pro porção de reagentes foi menor, isto $\vec{e}$, da ordem de 808. O período de tempo em que se observaram resultados positivos nas reaçōes de fixação do complemen to vai do $4^{\circ}$ ao $35^{\circ}$ dia e nas reaçōes do aglutineç̃o microscōpica do $7^{\circ}$ ao $35^{\circ} \mathrm{dil}$, embo ra a maioria das reaçōes positivas tenha sido ob servada entre $07^{\circ}$ ○ $2^{\circ}$ dia en ambos os grupos de aninais (TABELAS 12 - 13).

Os tiftulos de anticorpos medidos pelas rea çồes de aglutinação microsçôpica e de fixação do colmplemento, em ambos os grupos de animais estão apresentados nes TABELAS 14 e 15 . 
TABELA 2 - Frequência de cães reagentes e não reagentes às reações de soro aglutinação microscōpica e de fixação do complemento, frente ao antígeno homólogo, antes e após a inoculação com Leptospira in terrogans sorotipo icterohaemorrhagiae. São Paulo, 1979.

\begin{tabular}{|c|c|c|c|c|c|c|c|c|}
\hline \multicolumn{5}{|c|}{$\begin{array}{cc}\text { Reação } & \text { de } \\
\text { Soroaglutinação Microscópica }\end{array}$} & \multicolumn{4}{|c|}{$\begin{array}{l}\text { Reação } \\
\text { Fixação do } \\
\text { do }\end{array}$} \\
\hline $\begin{array}{l}\text { Tempo } \\
\text { (Dias) }\end{array}$ & Reagentes & $\begin{array}{c}\text { Não } \\
\text { Reagentes }\end{array}$ & Total & $\stackrel{\stackrel{\circ}{0}}{\text { Reagentes }}$ & Reagentes & $\begin{array}{c}\text { Não } \\
\text { Reagentes }\end{array}$ & Total & $\stackrel{q}{:}$ \\
\hline 0 & 0 & 15 & 15 & 0 & 0 & 15 & 15 & 0 \\
\hline 4 & 0 & 15 & 15 & 0 & 7 & 8 & 15 & 47 \\
\hline 7 & 12 & 3 & 15 & 80 & 13 & 2 & 15 & 87 \\
\hline 10 & 15 & 0 & 15 & 100 & 15 & 0 & 15 & 100 \\
\hline 14 & 15 & 0 & 15 & 100 & 15 & 0 & 15 & 100 \\
\hline 21 & 15 & 0 & 15 & 100 & 14 & 1 & 15 & 93 \\
\hline 28 & 13 & 0 & 13 & 100 & 9 & 4 & 13 & 69 \\
\hline 35 & 12 & 1 & 13 & 95 & 7 & 6 & 13 & 54 \\
\hline 42 & 9 & 3 & 12 & 75 & 4 & 8 & 12 & 33 \\
\hline 49 & 8 & 3 & 11 & 73 & 2 & 9 & 11 & 18 \\
\hline 56 & 4 & 4 & 8 & 50 & 0 & 8 & 8 & 0 \\
\hline
\end{tabular}


TABELA 3 - Frequência de cães reagentes e não reagentes às reaçōes de soro aglutinação microscópica e de fixação do complemento, frente ao antígeno homólogo, antes e após a inoculação com Leptospira in terrogans sorotipo canicola. São Paulo, 1979.

\begin{tabular}{|c|c|c|c|c|c|c|c|c|}
\hline \multicolumn{5}{|c|}{$\begin{array}{c}\text { Reação } \\
\text { Soroaglutinação Microscópica }\end{array}$} & \multicolumn{4}{|c|}{$\begin{array}{ll}\operatorname{Re} a c ̧ a ̃ o \\
\text { Fixação do }\end{array}$} \\
\hline $\begin{array}{l}\text { Tempo } \\
\text { (Dias) }\end{array}$ & Reagentes & $\begin{array}{c}\text { Não } \\
\text { Reagentes }\end{array}$ & Tota 1 & $\stackrel{q}{q}$ & Reagentes & $\begin{array}{c}\text { Não } \\
\text { Reagentes }\end{array}$ & Total & $\stackrel{\circ}{\circ}$ Reagentes \\
\hline 0 & 0 & 15 & 15 & 0 & 0 & 15 & 15 & 0 \\
\hline 4 & 0 & 15 & 15 & 0 & 8 & 7 & 15 & 53 \\
\hline 7 & 8 & 7 & 15 & 53 & 15 & 0 & 15 & 100 \\
\hline 10 & 15 & 0 & 15 & 100 & 15 & 0 & 15 & 100 \\
\hline 14 & 15 & 0 & 15 & 100 & 15 & 0 & 15 & 100 \\
\hline 21 & 15 & 0 & 15 & 100 & 14 & 1 & 15 & 93 \\
\hline 28 & 15 & 0 & 15 & 100 & 13 & 2 & 15 & 87 \\
\hline 35 & 15 & 0 & 15 & 100 & 12 & 3 & 15 & 80 \\
\hline 42 & 14 & 1 & 15 & 93 & 8 & 7 & 15 & 53 \\
\hline 49 & 13 & 2 & 15 & 87 & 7 & 8 & 15 & 47 \\
\hline 56 & 9 & 2 & 11 & 82 & 3 & 8 & 11 & 27 \\
\hline 63 & 8 & 2 & 10 & 80 & 0 & 10 & 10 & 0 \\
\hline
\end{tabular}


TABELA 4 - Títulos de anticorpos medidos pela reação de aglutinação microscópica frente ao antígeno homólogo, em cães inoculados com Leptospira inter rogans sorotipo icterohaemorrhagiae. São Paulo, 1979.

\begin{tabular}{|c|c|c|c|c|c|c|c|c|c|c|c|}
\hline Animal $\mathrm{N}^{\circ}$ Tempo (dias) & 0 & 4 & 7 & 10 & 14 & 21 & 28 & 35 & 42 & 49 & 56 \\
\hline 1 & - & - & 200 & 200 & 400 & 100 & * & & & & \\
\hline 2 & - & - & 100 & 800 & 800 & 800 & 400 & 100 & 100 & 100 & - \\
\hline 3 & - & - & 100 & 400 & 800 & 6400 & 1600 & 800 & 800 & 100 & * \\
\hline 4 & - & - & 100 & 200 & 1600 & 3200 & 400 & 400 & 400 & 200 & * \\
\hline 5 & - & - & - & 800 & 800 & 800 & 800 & 200 & 100 & 100 & 100 \\
\hline 6 & - & - & 100 & 100 & 800 & 1600 & $\star$ & & & & \\
\hline 7 & - & - & 800 & 1600 & 1600 & 1600 & 1600 & 800 & 400 & - & - \\
\hline 8 & - & - & 200 & 200 & 400 & 400 & 200 & - & - & - & - \\
\hline 9 & - & - & 200 & 800 & 800 & 800 & 100 & 100 & - & - & * \\
\hline 10 & - & - & 200 & 800 & 800 & 6400 & 800 & 100 & 100 & 100 & 100 \\
\hline 11 & - & - & 100 & 1600 & 6400 & 6400 & 6400 & 1600 & 800 & 400 & 400 \\
\hline 12 & - & - & 200 & 800 & 800 & 6400 & 1600 & 1600 & 800 & 800 & 400 \\
\hline 13 & - & - & - & 400 & 400 & 800 & 400 & 100 & * & & \\
\hline 14 & - & - & 800 & 1600 & 3200 & 3200 & 3200 & 100 & 100 & 100 & - \\
\hline 15 & - & - & - & 200 & 200 & 1600 & 1600 & 800 & 400 & $\star$ & \\
\hline
\end{tabular}


TABElA 5 - Evolução dos títulos de anticorpos medidos pela reação de fixação do complemento frente ao antígeno homólogo, em cães inoculados com Leptospira interrogans sorotipo icterohaemorrhagiae. São Paulo,1979.

\begin{tabular}{|c|c|c|c|c|c|c|c|c|c|c|c|}
\hline Animal $\mathrm{N}^{\circ}$ Tempo (dias) & 0 & 4 & 7 & 10 & 14 & 21 & 28 & 35 & 42 & 49 & 56 \\
\hline 1 & - & - & 110 & 150 & 190 & 80 & * & & & & \\
\hline 2 & - & - & 110 & 440 & 560 & 360 & 20 & - & - & - & - \\
\hline 3 & - & - & 40 & 50 & 160 & 640 & 640 & 640 & 640 & 640 & * \\
\hline 4 & - & 360 & 640 & 640 & 640 & 80 & 60 & 5 & 5 & 5 & * \\
\hline 5 & - & 80 & 450 & 450 & 280 & 180 & 90 & 50 & 50 & - & - \\
\hline 6 & - & - & - & 5 & 10 & 440 & * & & & & \\
\hline 7 & - & 160 & $>640$ & $>640$ & 540 & 440 & 120 & - & - & - & - \\
\hline 8 & - & 80 & $>640$ & $>640$ & 540 & 440 & 120 & - & - & - & - \\
\hline 9 & - & 40 & 350 & 350 & 130 & 70 & - & - & - & - & * \\
\hline 10 & - & - & 30 & 30 & 40 & - & - & - & - & - & - \\
\hline 11 & - & 40 & 250 & $>640$ & $>640$ & $>640$ & 620 & 480 & 100 & - & - \\
\hline 12 & - & - & $>640$ & 610 & 340 & 60 & - & - & - & - & - \\
\hline 13 & - & - & $>640$ & $>640$ & 120 & 30 & - & - & * & & \\
\hline 14 & - & $>640$ & $>640$ & $>640$ & $>640$ & $=640$ & $>640$ & 340 & - & - & - \\
\hline 15 & - & - & - & 640 & 640 & 640 & 40 & 40 & - & * & \\
\hline
\end{tabular}


TABELA 6 - Evolução dos títulos de anticorpos medidos pela reação de aglutinação microscópica frente ao antígeno homölogo, em cães inoculados com Leptospira in terrogans sorotipo canicola. São Paulo, 1979.

\begin{tabular}{|c|c|c|c|c|c|c|c|c|c|c|c|c|}
\hline Anima1 $\mathrm{N}^{\circ}$ Tempo (dias) & 0 & 4 & 7 & 10 & 14 & 21 & 28 & 35 & 42 & 49 & 50 & 63 \\
\hline 1 & - & - & 800 & 1600 & 1600 & 400 & 400 & 400 & 400 & 200 & 200 & - \\
\hline 2 & - & - & 200 & 800 & 6400 & 6400 & 6400 & 6400 & 6400 & 6400 & 3200 & 300 \\
\hline 3 & - & - & - & 800 & 3200 & 6400 & 6400 & 6400 & 3200 & 3200 & 1600 & 800 \\
\hline 4 & - & - & 100 & 800 & 1600 & 6400 & 1600 & 200 & 200 & 200 & 200 & 100 \\
\hline 5 & - & - & - & 800 & 6400 & 6400 & 6400 & 6400 & 6400 & 1600 & * & \\
\hline 6 & - & - & 200 & 800 & 1600 & 1600 & 200 & 200 & - & - & - & * \\
\hline 7 & - & - & 400 & 800 & 1600 & 1600 & 1600 & 200 & 200 & 100 & 100 & 800 \\
\hline 8 & - & - & - & 1600 & 1600 & 3200 & 3200 & 400 & 200 & 200 & * & \\
\hline 9 & - & - & 400 & 800 & 6400 & 6400 & 6400 & 3200 & 3200 & 3200 & 1600 & 800 \\
\hline 10 & - & - & - & 1600 & 1600 & 1600 & 800 & 200 & 100 & - & - & - \\
\hline 11 & - & - & 200 & 1600 & 1600 & 1600 & 1600 & 800 & 200 & 200 & 200 & 200 \\
\hline 12 & - & - & 200 & 800 & 800 & 1600 & 200 & 200 & 200 & 200 & $\star$ & \\
\hline 13 & - & - & - & 3200 & 6400 & 6400 & 1600 & 1600 & 400 & 200 & * & \\
\hline 14 & - & - & - & 3200 & 3200 & 3200 & 3200 & 3200 & 800 & 100 & 100 & 100 \\
\hline 15 & - & - & - & 6400 & 6400 & 6400 & 3200 & 1600 & 1600 & 800 & 400 & 200 \\
\hline
\end{tabular}


TABELA 7 - Títulos dos anticorpos medidos pela reação de fixação de complemento frente ao antígeno homólogo, em cães inoculados com Leptospira inter rogans sorotipo canicola. São Paulo, 1979.

\begin{tabular}{|c|c|c|c|c|c|c|c|c|c|c|c|c|}
\hline Animal $\mathrm{N}^{\circ}$ Tempo (dias) & 0 & 4 & 7 & 10 & 14 & 21 & 28 & 35 & 42 & 49 & 56 & 63 \\
\hline 1 & - & 160 & $>640$ & 410 & 270 & 60 & - & - & - & - & - & - \\
\hline 2 & - & - & 90 & $>640$ & 420 & 400 & 350 & 420 & 90 & - & - & - \\
\hline 3 & - & - & 270 & 550 & 640 & 640 & 640 & 350 & 350 & 210 & - & - \\
\hline 4 & - & 80 & 260 & $>640$ & $>640$ & $>640$ & 170 & - & - & - & - & - \\
\hline 5 & - & 160 & 160 & $>640$ & $>640$ & $>640$ & $>640$ & $>640$ & $>640$ & 600 & * & \\
\hline 6 & - & - & 180 & 180 & 200 & - & - & - & - & - & - & * \\
\hline 7 & - & 80 & 260 & 320 & 260 & 180 & 180 & 80 & 90 & 80 & 40 & - \\
\hline 8 & - & - & 640 & 320 & 260 & 240 & 240 & 130 & - & - & * & \\
\hline 9 & - & 80 & $>640$ & $>640$ & $>640$ & $>640$ & 640 & 560 & 220 & 160 & 80 & - \\
\hline 10 & - & - & $>640$ & $>640$ & 640 & 400 & 200 & 10 & 5 & - & - & - \\
\hline 11 & - & - & $>640$ & $>640$ & 640 & 640 & 370 & 160 & 80 & 80 & - & - \\
\hline 12 & - & 80 & 640 & 320 & 260 & 200 & 80 & 80 & - & - & * & \\
\hline 13 & - & 50 & 640 & 640 & 320 & 260 & 160 & 80 & - & - & * & \\
\hline 14 & - & - & $>640$ & 640 & 640 & 160 & 160 & 160 & 80 & 20 & - & - \\
\hline 15 & - & 27 & 360 & $>640$ & $>640$ & 640 & 640 & 320 & 160 & 110 & 80 & - \\
\hline
\end{tabular}




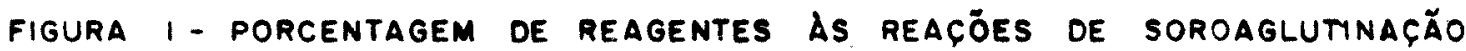
MICROSCÓPICA E DE FIXACÄO DO COMPLEMENTO FRENTE AO ANTIGENO HOMÓLOGO, ANTES E APÓS A INOCULAÇÃO COM LEPTOSPIRA INTERROGANS SOROTIPO ICTEROHAEMORRHAGIAE, SÃO PAULO, 1979.

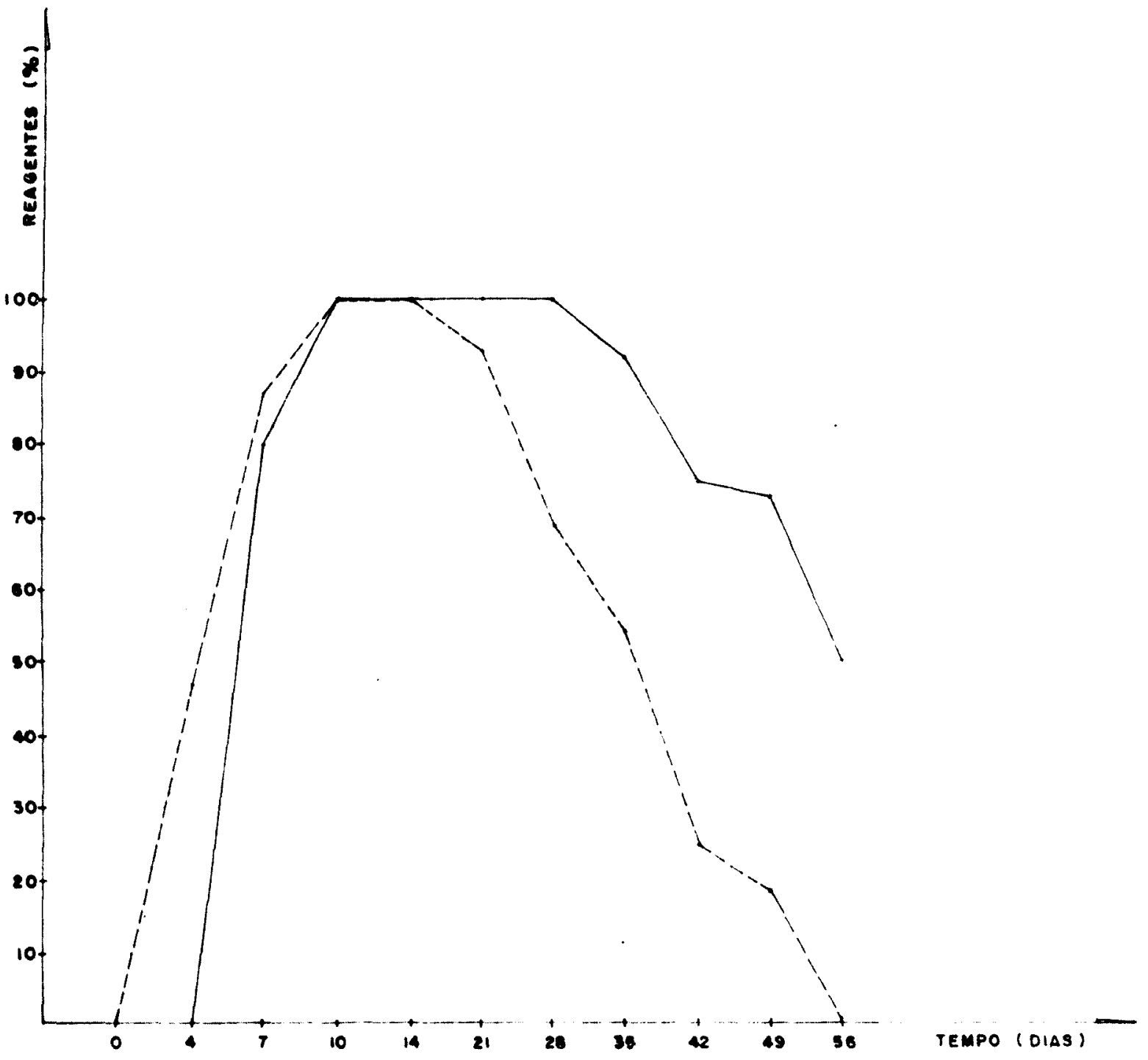

reagio de soronelutimagío microscópica.

reagio oe pixagko oo complenento. 
floura 2 - poncentaeem de reagentes ds reacöes de sonoaglutinaçäo MICROSCÓPICA E de FIXACÃo do COMPLEMEnTo FRENTE aO antiOENO MOMÓLOOO, ANTES E AMÓS A IMOCULACÁO COM LEPTOSPIRA imtrennocame sonotipo camicola, sh̆o paULo, 1979.

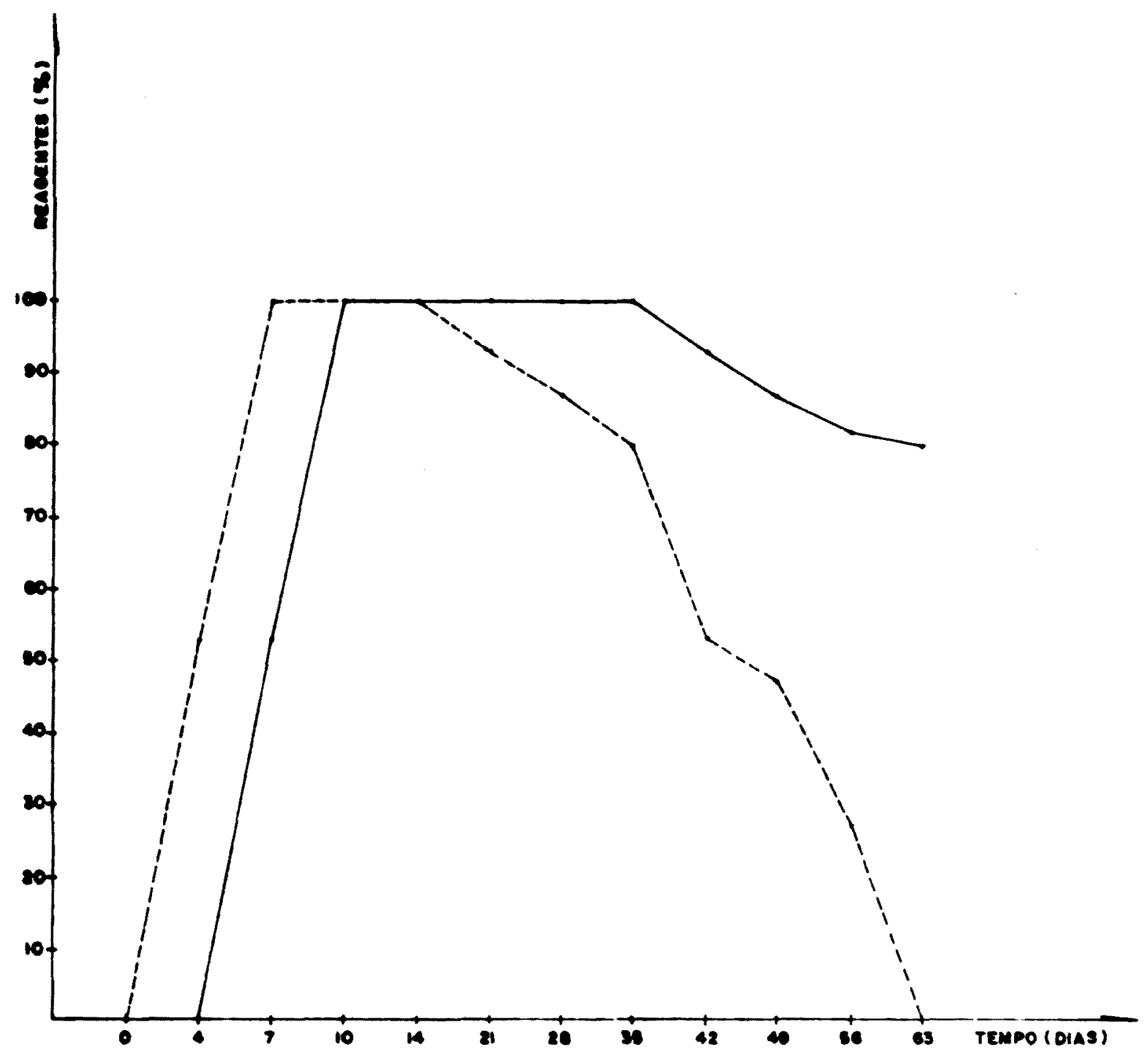

- REAGLio or sononelutimagĩo mienoscópica.

-..- maglo or pixaglo do complemento. 
TABELA 8 - Frequência de cães reagentes e não reagentes às reações de soro aglutinação microscôpica e de fixação do complemento frente ao antígeno Patoc I, antes e após a infecçāo experimental por Leptospira interrogans sorotipo icterohaemorrhagiae. São Paulo, 1979.

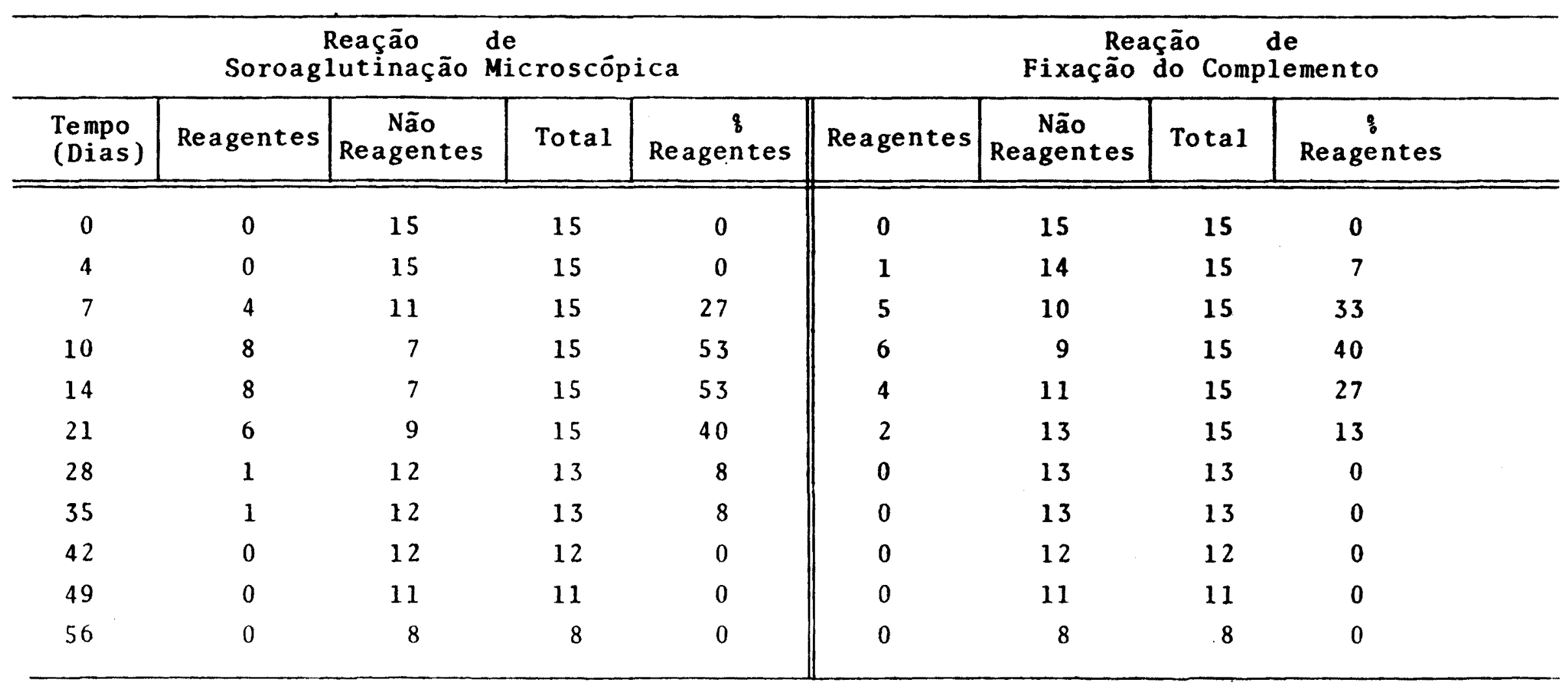


TABELA 9 - Frequência de cães reagentes e não reagentes às reações de soro aglutinação microscópica e de fixação do complemento frente ao antígeno Patoc I, antes e após inoculação com Leptospira inter rogans sorotipo canicola. São Paulo, 1979.

\begin{tabular}{|c|c|c|c|c|c|c|c|c|}
\hline \multicolumn{6}{|c|}{$\begin{array}{cc}\text { Reação } & \text { de } \\
\text { Soroaglutinação Microscópica }\end{array}$} & \multicolumn{3}{|c|}{$\begin{array}{c}\text { Reação de } \\
\text { Fixação do Complemento }\end{array}$} \\
\hline $\begin{array}{l}\text { Tempo } \\
\text { (Dias) }\end{array}$ & Reagentes & $\begin{array}{c}\text { Não } \\
\text { Reagentes }\end{array}$ & Total & Reagentes & Reagentes & $\begin{array}{c}\text { Não } \\
\text { Reagentes }\end{array}$ & Total & $\stackrel{q}{q}$ \\
\hline 0 & 0 & 15 & 15 & 0 & 0 & 15 & 15 & 0 \\
\hline 4 & 0 & 15 & 15 & 0 & 1 & 14 & 15 & 7 \\
\hline 7 & 3 & 12 & 15 & 20 & 2 & 13 & 15 & 13 \\
\hline 10 & 4 & 11 & 15 & 27 & 4 & 11 & 15 & 27 \\
\hline 14 & 5 & 10 & 15 & 33 & 4 & 11 & 15 & 27 \\
\hline 21 & 4 & 11 & 15 & 27 & 4 & 11 & 15 & 27 \\
\hline 28 & 1 & 14 & 15 & 7 & 0 & 15 & 15 & 0 \\
\hline 35 & 1 & 14 & 15 & 7 & 0 & 15 & 15 & 0 \\
\hline 42 & 1 & 14 & 15 & 7 & 0 & 15 & 15 & 0 \\
\hline 49 & 0 & 15 & 15 & 0 & 0 & 15 & 15 & 0 \\
\hline 56 & 0 & 11 & 11 & 0 & 0 & 11 & 11 & 0 \\
\hline 63 & 0 & 10 & 10 & 0 & 0 & 10 & 10 & 0 \\
\hline
\end{tabular}


TABELA 10 - Frequência de cães reagentes e não reagentes às reações de soro aglutinação microscópica e de fixação do complemento frente ao antígeno Rufino, antes e após inoculação com Leptospira inter rogans sorotipo icterohaemorhagiae. São Paulo, 1979.

\begin{tabular}{|c|c|c|c|c|c|c|c|c|}
\hline \multicolumn{6}{|c|}{$\begin{array}{l}\text { Reação - de } \\
\text { Soroaglutinaçāo Microscōpica }\end{array}$} & \multicolumn{3}{|c|}{ Fixação do do Complemento } \\
\hline $\begin{array}{r}\text { Tempo } \\
\text { (Dias) }\end{array}$ & Reagentes & $\begin{array}{c}\text { Não } \\
\text { Reagentes }\end{array}$ & Total & $\stackrel{\&}{q}$ & Reagentes & $\begin{array}{c}\text { Não } \\
\text { Reagentes }\end{array}$ & Tota 1 & $\stackrel{q}{q}$ \\
\hline 0 & 0 & 15 & 15 & 0 & 0 & 15 & 15 & 0 \\
\hline 4 & 0 & 15 & 15 & 0 & 0 & 15 & 15 & 0 \\
\hline 7 & 5 & 10 & 15 & 33 & 0 & 15 & 15 & 0 \\
\hline 10 & 7 & 8 & 15 & 53 & 0 & 15 & 15 & 0 \\
\hline 14 & 7 & 8 & 15 & 53 & 0 & 15 & 15 & 0 \\
\hline 21 & 4 & 11 & 15 & 27 & 0 & 15 & 15 & 0 \\
\hline 28 & 0 & 13 & 13 & 0 & 0 & 13 & 13 & 0 \\
\hline 35 & 0 & 13 & 13 & 0 & 0 & 13 & 13 & 0 \\
\hline 42 & 0 & 12 & 12 & 0 & 0 & 12 & 12 & 0 \\
\hline 49 & 0 & 11 & 11 & 0 & 0 & 11 & 11 & 0 \\
\hline 56 & 0 & 8 & 8 & 0 & 0 & 8 & 8 & 0 \\
\hline
\end{tabular}


TABELA 11 - Frequência de cães reagentes e não reagentes às reações de soro aglutinaçāo microscópica e de fixaçāo do complemento frente ao antigeno Rufino, antes e após inoculação com Leptospira inter rogans sorotipo canicola. São Paulo, 1979.

\begin{tabular}{|c|c|c|c|c|c|c|c|c|}
\hline \multicolumn{6}{|c|}{$\begin{array}{c}\text { Reação } \\
\text { Soroaglutinação Microscópica }\end{array}$} & \multicolumn{3}{|c|}{ Fixação do do Complemento } \\
\hline $\begin{array}{l}\text { Tempo } \\
\text { (Dias) }\end{array}$ & Reagentes & $\begin{array}{c}\text { Não } \\
\text { Reagentes }\end{array}$ & Total & Reagentes & Reagentes & $\begin{array}{c}\text { Não } \\
\text { Reagentes }\end{array}$ & Total & $\stackrel{8}{\text { Reagentes }}$ \\
\hline $\mathbf{0}$ & 0 & 15 & 15 & 0 & $\mathbf{0}$ & 15 & 15 & $\mathbf{0}$ \\
\hline 4 & 0 & 15 & 15 & 0 & 0 & 15 & 15 & $\mathbf{0}$ \\
\hline 7 & 0 & 15 & 15 & 0 & 0 & 15 & 15 & 0 \\
\hline 10 & 3 & 12 & 15 & 20 & 0 & 15 & 15 & 0 \\
\hline 14 & 5 & 10 & 15 & 33 & 0 & 15 & 15 & 0 \\
\hline 21 & 8 & 7 & 15 & 53 & 0 & 15 & 15 & 0 \\
\hline 28 & 8 & 7 & 15 & 53 & $\mathbf{0}$ & 15 & 15 & 0 \\
\hline 35 & 7 & 8 & 15 & 47 & $\mathbf{0}$ & 15 & 15 & 0 \\
\hline 42 & 4 & 11 & 15 & 27 & 0 & 15 & 15 & 0 \\
\hline 49 & 0 & 15 & 15 & 0 & 0 & 15 & 15 & 0 \\
\hline 56 & 0 & 11 & 11 & 0 & 0 & 11 & 11 & 0 \\
\hline 63 & 0 & 10 & 10 & 0 & 0 & 10 & 10 & 0 \\
\hline
\end{tabular}


TABELA 12 - Frequência de cães reagentes e não reagentes às reações de soro aglutinação microscópica e de fixação do complemento frente ao antígeno Buenos Aires, antes e após inoculação com Leptospira interrogans sorotipo icterohaemorrhagiae. São Paulo, 1979.

\begin{tabular}{|c|c|c|c|c|c|c|c|c|}
\hline \multicolumn{5}{|c|}{$\begin{array}{cc}\text { Reação } & \text { de } \\
\text { Soroaglutinação Microscōpica }\end{array}$} & \multicolumn{4}{|c|}{ Fixação do do } \\
\hline $\begin{array}{l}\text { Tempo } \\
\text { (Dias) }\end{array}$ & Reagentes & $\begin{array}{c}\text { Não } \\
\text { Reagentes }\end{array}$ & Total & Reagentes & Reagentes & $\begin{array}{c}\text { Nāo } \\
\text { Reagentes }\end{array}$ & Total & Reagentes \\
\hline 0 & 0 & 15 & 15 & 0 & 0 & 15 & 15 & 0 \\
\hline 4 & 0 & 15 & 15 & 0 & 2 & 13 & 15 & 13 \\
\hline 7 & 3 & 12 & 15 & 20 & 11 & 4 & 15 & 73 \\
\hline 10 & 13 & 2 & 15 & 87 & 12 & 4 & 15 & 80 \\
\hline 14 & 13 & 2 & 15 & 87 & 11 & 4 & 15 & 73 \\
\hline 21 & 10 & 5 & 15 & 67 & 5 & 10 & 15 & 33 \\
\hline 28 & 7 & 6 & 13 & 54 & 2 & 11 & 13 & 15 \\
\hline 35 & 3 & 10 & 13 & 23 & 2 & 11 & 13 & 15 \\
\hline 42 & 0 & 12 & 12 & 0 & 0 & 12 & 12 & 0 \\
\hline 49 & 0 & 11 & 11 & 0 & 0 & 11 & 11 & 0 \\
\hline 56 & 0 & 8 & 8 & 0 & 0 & 8 & 8 & 0 \\
\hline
\end{tabular}


TABELA 13 - Frequência de cães reagentes e não reagentes às reaçōes de soro aglutinação microscópica e de fixação do complemento frente ao antígeno Buenos Aires, antes e após inoculação com Leptospira interrogans sorotipo canicola. São Paulo, 1979.

\begin{tabular}{|c|c|c|c|c|c|c|c|c|}
\hline \multicolumn{5}{|c|}{$\begin{array}{cc}\text { Reação } & \text { de } \\
\text { Soroaglutinação } & \text { Microscópica }\end{array}$} & \multicolumn{4}{|c|}{ Fixação do do Complemento } \\
\hline $\begin{array}{l}\text { Tempo } \\
\text { (Dias) }\end{array}$ & Reagentes & $\begin{array}{c}\text { Não } \\
\text { Reagentes }\end{array}$ & Total & $\stackrel{\&}{\&}$ & Reagentes & $\begin{array}{c}\text { Não } \\
\text { Reagentes }\end{array}$ & Total & $\stackrel{\text { s }}{\text { Reagentes }}$ \\
\hline 0 & 0 & 15 & 15 & 0 & 0 & 15 & 15 & 0 \\
\hline 4 & 0 & 15 & 15 & 0 & 1 & 14 & 15 & 7 \\
\hline 7 & 3 & 13 & 15 & 20 & 9 & 6 & 15 & 60 \\
\hline 10 & 12 & 3 & 15 & 80 & 12 & 3 & 15 & 80 \\
\hline 14 & 12 & 3 & 15 & 80 & 7 & 8 & 15 & 53 \\
\hline 21 & 10 & 5 & 15 & 67 & 2 & 13 & 15 & 13 \\
\hline 28 & 6 & 9 & 15 & 40 & 0 & 15 & 15 & 0 \\
\hline 35 & 2 & 13 & 15 & 13 & 0 & 15 & 15 & 0 \\
\hline 42 & 0 & 15 & 15 & 0 & 0 & 15 & 15 & 0 \\
\hline 49 & 0 & 15 & 15 & 0 & 0 & 15 & 15 & 0 \\
\hline 56 & 0 & 11 & 11 & 0 & 0 & 11 & 11 & 0 \\
\hline 63 & 0 & 10 & 10 & 0 & 0 & 10 & 10 & 0 \\
\hline
\end{tabular}


TABELA 14 - Títulos de anticorpos medidos pelas reações de aglutinação microscópica e de fixação do complemento frente ao antígeno Buenos Aires, en cães inoculados com Leptospira interrogans sorotipo icterohaemorrhagiae. São Paulo, 1979 .

\begin{tabular}{|c|c|c|c|c|c|c|c|c|c|c|c|c|c|c|c|c|c|c|c|c|c|c|}
\hline Tempo (dias) & \multicolumn{2}{|c|}{0} & \multicolumn{2}{|c|}{4} & \multicolumn{2}{|c|}{7} & \multicolumn{2}{|c|}{10} & \multicolumn{2}{|c|}{14} & \multicolumn{2}{|c|}{21} & \multicolumn{2}{|c|}{28} & \multicolumn{2}{|c|}{35} & \multicolumn{2}{|c|}{42} & \multicolumn{2}{|c|}{49} & \multicolumn{2}{|c|}{56} \\
\hline$\frac{\text { Reação }}{\text { Animal ì }}$ & $\mathrm{SA}$ & $\mathrm{FC}$ & SA & $\mathrm{FC}$ & SA & $\mathrm{FC}$ & SA & $\mathrm{FC}$ & SA & $\mathrm{FC}$ & $\mathrm{SA}$ & FC & SA & $\mathrm{FC}$ & $\mathrm{SA}$ & FC & SA & $\mathrm{FC}$ & $\mathrm{SA}$ & $\mathrm{FC}$ & $\mathrm{SA}$ & FC \\
\hline 1 & - & - & - & 5 & - & 10 & 100 & 5 & 200 & - & 100 & - & * & & & & & & & & & \\
\hline 2 & - & - & - & - & - & 20 & 100 & 10 & 100 & 10 & 100 & 10 & 100 & - & - & - & - & - & - & - & - & - \\
\hline 3 & - & - & - & - & - & - & - & - & - & - & - & - & - & - & - & - & - & - & - & - & * & \\
\hline 4 & - & - & - & - & - & - & - & - & - & - & - & - & - & - & - & - & - & - & - & - & $\star$ & \\
\hline 5 & - & - & - & - & - & 8 & 100 & 10 & 100 & 10 & 100 & 10 & 100 & - & - & - & - & - & - & - & - & - \\
\hline 6 & - & - & - & - & - & 5 & 100 & 5 & 100 & 5 & - & - & $\star$ & & & & & & & & & \\
\hline 7 & - & - & - & 6 & 100 & 5 & 100 & - & 100 & - & 100 & - & - & - & - & - & - & - & - & - & - & - \\
\hline 8 & - & - & - & - & 100 & 20 & 100 & 20 & 100 & 15 & 100 & - & - & - & - & - & - & - & - & - & - & - \\
\hline 9 & - & - & - & - & - & 20 & 100 & 20 & 100 & 10 & - & - & - & - & - & - & - & - & - & - & $\star$ & \\
\hline 10 & - & - & - & - & - & - & 100 & 20 & 100 & 20 & 100 & - & 100 & - & - & - & - & - & - & - & - & - \\
\hline 11 & - & - & - & - & 100 & 20 & 100 & 20 & 100 & 10 & 100 & - & 100 & - & - & - & - & - & - & - & - & - \\
\hline 12 & - & - & - & - & - & - & 100 & 20 & 100 & 20 & 100 & 20 & 100 & - & 100 & - & - & - & - & - & - & - \\
\hline 13 & - & - & - & - & - & 10 & 100 & 10 & 100 & 10 & - & - & - & - & - & - & * & & & & & \\
\hline 14 & - & - & - & - & - & 20 & 200 & 30 & 200 & 20 & 100 & 20 & 100 & 10 & 100 & 5 & - & - & - & - & - & - \\
\hline 15 & - & - & - & - & - & 5 & 100 & 30 & 100 & 20 & 100 & 5 & 100 & 5 & 100 & 5 & - & - & * & & & \\
\hline
\end{tabular}


TABELA 15 - Títulos de anticorpos medidos pela reação de soroaglutinação microscópica e de fixa ção do complemento frente ao antígeno Buenos Aires, em cāes inoculados com Leptospi ra interrogans sorotipo canicola. São Paulo, 1979.

\begin{tabular}{|c|c|c|c|c|c|c|c|c|c|c|c|c|c|c|c|c|c|c|c|c|c|c|c|c|}
\hline \multirow{2}{*}{$\begin{array}{l}\text { Tempo (dias) } \\
\text { Rearān } \\
\text { Animal } N^{9}\end{array}$} & \multicolumn{2}{|c|}{0} & \multicolumn{2}{|c|}{4} & \multicolumn{2}{|l|}{7} & \multicolumn{2}{|c|}{10} & \multicolumn{2}{|c|}{14} & \multicolumn{2}{|c|}{21} & \multicolumn{2}{|c|}{28} & \multicolumn{2}{|c|}{35} & \multicolumn{2}{|c|}{42} & \multicolumn{2}{|c|}{49} & \multicolumn{2}{|c|}{55} & \multicolumn{2}{|c|}{6.3} \\
\hline & SA & FC & SA & $\mathrm{FC}$ & $\mathrm{SA}$ & $\mathrm{FC}$ & SA & FC & $\mathrm{SA}$ & $\mathrm{FC}$ & $\mathrm{SA}$ & $\mathrm{FC}$ & $\mathrm{SA}$ & FC & SA 1 & $\mathrm{FC}$ & SA. & Fr. & $\mathrm{SA}$ & FC & Sf. & FS & S: & FC \\
\hline 1 & - & - & - & - & - & 20 & 100 & 20 & 100 & - & 100 & - & 100 & - & 100 & - & - & - & - & - & - & - & - & - \\
\hline 2 & - & - & - & - & - & 5 & 100 & 5 & 100 & 5 & 100 & - & 100 & - & - & - & - & - & - & - & - & - & - & - \\
\hline 3 & - & - & - & - & - & - & - & - & - & - & & - & - & - & - & - & - & - & - & - & - & - & - & - \\
\hline 4 & - & - & - & 5 & 100 & 20 & 100 & 5 & 100 & 5 & 100 & - & 100 & - & - & - & - & - & - & - & - & - & - & - \\
\hline 5 & - & - & - & - & - & - & 100 & 50 & 200 & 20 & 100 & 51 & 100 & - & - & - & - & - & - & - & * & & & \\
\hline 6 & - & - & - & - & - & - & - & - & - & - & - & - & - & - & - & - & - & - & - & - & - & - & * & \\
\hline 7 & - & - & - & - & - & - & - & - & - & - & - & - & - & - & - & - & - & - & - & - & - & - & - & - \\
\hline 8 & - & - & - & 30 & 100 & 40 & 100 & 30 & 100 & - & - & - & - & - & - & - & - & - & - & - & * & & & \\
\hline 9 & - & - & - & - & - & 5 & 100 & 5 & 100 & - & 100 & $1-$ & - & - & - & - & - & - & - & - & - & - & - & - \\
\hline 10 & - & - & - & - & - & - & 100 & 5 & 100 & 5 & 100 & - & 100 & - & - & - & - & - & - & - & - & - & - & - \\
\hline 11 & - & - & - & - & - & - & 100 & 10 & 100 & 10 & & - & - & - & - & - & - & - & - & - & - & - & - & - \\
\hline 12 & - & - & - & - & - & 10 & 100 & 10 & 100 & - & 100 & - & - & - & - & - & - & - & - & - & * & & & \\
\hline 13 & - & - & - & - & - & 5 & 100 & 10 & 100 & 5 & 100 & - & - & - & - & - & - & - & - & - & * & & & \\
\hline 14 & - & - & - & - & - & 10 & 100 & 5 & 100 & - & 100 & -1 & 100 & - & 100 & - & - & - & - & - & - & - & - & - \\
\hline 15 & - & - & - & -1 & 100 & 10 & 100 & 20 & 100 & 10 & 100 & 5 & - & - & - & - & - & - & - & - & - & - & - & - \\
\hline
\end{tabular}

* = óbitos no decurso do experimento.

$\mathrm{SA}=$ soroaglutinação microscōpica.

$\mathrm{FC}=$ fixaçăo do complemento. 
5. DISCUSSAOO.

A soroconversão ou o aumento gradativo dos títu los em duas amostras de soros coletados com intervalos de 1 ou de 2 semanas, considerados requisitos básicos para se confirmar - diagnöstico de leptospirose em animais com ou sem sintomatolo gia clínica, foram observados em todos os animais do grupo I, inoculados com leptospiras patogênicas do sorotipo icterohaemor rhagiae e do grupo II, inoculados com leptospiras do sorotipo canicola. A imune resposta foi räpida, podendo observar-se an ticorpos humorais revelados pela reação de fixação do complemen to, a partir do $4^{\circ}$ dia após a inoculação experimental em ambos os grupos e pela reação de aglutinação microscópica,a partir do $7^{9}$ dia.

Existem diversidades de opiniões em relação ao inicio do aparecimento dos anticorpos aglutinantes nos soros dos animais infectados, como as de ALSTON \& BROOM ${ }^{4}(1958)$, segundo os quais as aglutininas são detectáveis na circulação sanguínea após o $7^{\circ}$ dia de doença, como ocorreu também no presente experi mento, as de TAYLOR e col., ${ }^{48}(1970)$, que observaram anticorpos humorais em animais inoculados com leptospiras do sorotipo canicola entre $010^{\circ}$ e $14^{\circ}$ dia. Essas variaçōes podem ser ex plicadas por diferenças individuais de resposta imunológica aó mesmo estímulo, como também, podem estar na dependência dos tí tulos considerados positivos. E possível que, a partir de di luições mais baixas, a positividade fosse de $100 \%$ no $7^{\circ}$ dia, po dendo inclusive, encontrar-se animais reagentes no $4^{\circ}$ dia após a inoculação, como foi observado por COMBIESCO e col., 14 (1960), em seres humanos. MENGES e col. ${ }^{30}$ (1960) citam o aparecimento de anticorpos circulantes em títulos menores que 50 no 69 dia a pós a inoculação experimental de cães com o sorotipo pomona. En tretanto, seguindo os conceitos estabelecidos por SANTA ROSA $4 \overline{2}$ (1970), sempre utilizamos a diluição inicial de $1: 100$, conside rando assim, o título minimo significativo igual a 10019 . 
A precocidade da reação de fixação do complemen to em revelar anticorpos antileptospiras quando comparada à rea ção de aglutinação microscópica é citada na literatura, em rela ção ao soros humanos por STURDZA e col.., ${ }^{46}(1960)$ e em suínos $2 \overline{3}$ e bovinos 24,36 infectados experimentalmente.

A anālise das TABELAS 2 e 3 e FIGURAS 1 e 2 , de monstra que os anticorpos fixadores do complemento sāo observa dos mais precocemente que as aglutininas, tanto no soro dos cães infectados pelo sorotipo icterohaemorrhagiae como nos infecta dos pelo sorotipo canicola, sendo em alguns casos, os títulos bas tante elevados mesmo decorridos apenas 4 dias após a infecção experimental.

No decurso da segunda semana, pode observar-se um paralelismo entre os resultados das reações de fixação do com plemento e aglutinação microscópica, fato jă salientado por inú meros pesquisadores, quer nos espécimes caninos 34 , bovinos 41 , 36 , suínos 23 como também, no homem 39,54 . Apōs trés a quatro semanas, pode observar-se pela reação de fixação do complemento em ambos os grupos, a diminuição do número de reagentes, ao pas so que as aglutininas séricas persistiram na circulação por um período maior de tempo.

As imuneglobulinas do tipo $M$, produzidas precoce mente como resposta á infecção leptospírica são as responsāveis pe las reaçōes de soroaglutinação positivas, como demonstraram HAN SON $^{20}$ (1973) e MORRIS \& HOUSSAINI 31 (1974). Entretanto, a at $\bar{i}$ vidade aglutinante do soro não estā restrita apenas à classe IgM de anticorpos como foi sugerida por HANSON 20 (1973), mas tam bém, associada à presença de anticorpos do tipo IgG, que apare. cem mais tardiamente na circulação sanguínea, permanecendo po rém por um período maior de tempo. Destarte, a reação de aglu tinação microscópica permanece positiva por um período longo de tempo, detectando anticorpos residuais do tipo IgG. A reaçãode fixação do complemento parece revelar principalmente anticorpos humorais do tipo IgM, jā que não nermanece positivo por um período longo de tempo, como ocorre na reação de aglutinação microscōpi ca, que detecta ambos os tipos de anticorpos. 
No presente trabalho, confirmou-se o desempenho irregular e pouco satisfatório da leptospira aquícola Patoc I quando utilizada como antígeno único nas provas de soroaglutina ção microscópica ou de fixação do complemento, para o diagnóstí co da leptospirose canina pelos sorotipos icterohaemorrhagiae ou canicola, fato anteriormente citado por outros autores 11,2 , $32, \frac{43}{43}$

Embora os autores sejam concordes em salientar que existe uma diversidade de comportamento da estirpe Patoc I frente aos soros humanos e animais positivos para leptospiras pa togênicas $17,1,44$, poucas hipöteses foram formuladas para se justificar essa diferença. Para NICOLESCO \& LELUTIU 32, (1967) uma boa concordância entre os resultados positivos obtidos com - emprego de sorotipos patogênicos e o antígeno Patoc I indica infeçōes recentes, enquanto a positividade apenas para os soro tipos patogênicos pode ser interpretada como sinal de infecçōes mais antigas. Pelos dados obtidos, essa hipótese deve ser re jeitada, pois nos períodos pós-inoculação utilizados no presen te experimento, não se observou em nenhum momento, uma concor dância que fosse alta o suficiente para recomendar o uso do an tígeno Patoc I na reação de fixação do complemento ou de agluti nação microscōpica para o diagnóstico da leptospirose em cães infectados recentemente.

Segundo TURNER 50 (1968) essa variação no comportamento pode ser explicada pelas diferenças imunológicas existen tes entre as espécies animais, ocorrendo portanto, variações na resposta a um mesmo estímulo antigênico.

Entretanto, cabe salientar que, mesmo no diagnōs tico da leptospirose humana, no qual é usada rotineiramente co mo antígeno de triagem, existe uma variabilidade nos resultados obtidos com o emprego da estirpe Patoc I, indicando que a sensi bilidade $\vec{e}$ alta apenas nas infecções determinadas por alguns so rotipos como icterohaemorrhagiae, pomona, canicola ou copenhage $\underline{n i}^{2}, 18,15, \overline{22}$, sendo mais baixa, em torno de $50 \%$ quando as in fecções são causadas por outros sorotipos 18,22 . 
A porcentagem de animais reagentes à reação de soroaglutinação microscópica ao antígeno Rufino $(60 \%)$ em ambos os grupos experimentais, foi maior do que a verificada ao se em pregar a estirpe Patoc I, sendo entretanto bastante inferior a concordância de 1008 obtida por CACCHIONE e col., 9 (1971) e de 948 obtida pelos mesmos autores 10 em 1972. Foi tambëm diferen te dos resultados observados por SANTA ROSA 43 (1977) que, obteve uma concordância de apenas 2.58 entre os resultados de aglu tinação microscópica com soros de cães reagentes para os soroti pos icterohaemorrhagiae e canicola e os resultados obtidos com o emprego da estirpe Rufino nessa mesma reação.

Os resultados obtidos nas reações de fixação do complemento atravês do emprego dos antígenos homólogos e dos an tígenos preparados com as estirpes Patoc $I$ e Buenos Aires emanios os grupos experimentais, foram quase sempre concordantes com os obtidos nas reaçōes de soroaglutinação microscópica frente aos mesmos antigenos. Entretanto, quando se empregou o antígeno pre parado com a estirpe Rufino nas reações de fixação do complemen to frente aos soros dos cães infectados pelos sorotipos ictero haemorrhagiae ou canicola nāo se observou nenhuma reação pos tiva, fato este difícil de ser explicado à luz dos conhecimen tos atuais.

Os resultados obtidos pelo emprego da estirpe Bue nos Aires nas reações de aglutinação microscōpica e de fixação do complemento, com as amostras de soros de cães infectados pe los sorotipos icterohaemorrhagiae ou canicola, sugerem ser esta estirpe a que melhor se adapta ao diagnóstico da leptospirose ca nina por esses sorotipos. Não se pode entretanto, recomendā-10 co mo antígeno unico de triagem, pois a sensibilidade de $87 \%$ para - $1^{\circ}$ grupo e de 808 para $2^{\circ}$ grupo não foi suficientemente al ta.

Duas das características observadas quando se tes tou a estirpe Buenos Aires em ambas as reaçōes foram a precocida de e a homogeneidade da resposta. As reações positivas na pro va de fixaçāo do complemento, como se observam nas TABELAS 12 e 
13 ocorreram entre $07^{\circ}$ e $1^{\circ}$ dia pós-infecção, e na proya de soroaglutinaçāo microscópica entre o $10^{\circ}$ e $21^{\circ}$ dia em ambos os grupos de animais, nāo se observando reagentes após a 6 a. semana.

Durante as primeira semanas da infecção leptospí rica podem ocorrer as reaçōes heterólogas, às vêzes mais inten sas que as homólogas. Segundo KMETY ${ }^{25}$ (1958), essas reaçōes pá radoxais ocorrem mais comumente entre $06^{\circ}$ e $11^{\circ}$ dias da doença, em aproximadamente 508 das provas de soroaglutinação, sendo mais frequentes nas infecçōes por alguns sorotipos como sejoe, icte rohaemorrhagiae ou pomona. STURDZA e col., 45 (1960) considera ram a aglutinaçāo da estirpe Patoc I pelos soros de individuos do entes por outros sorotipos de leptospiras patogênicas como uma reação paradoxal. Todavia, para ADDAMIANO ${ }^{1}$ (1962) existe um antígeno comum à leptospira patogênica e à aquícola diferentedo antígeno gênero-específico comum a tōdas as leptospiras, não sendo portanto, apenas uma reação paradoxal.

\section{PALIT \& GULASEKHARAN 35 (1973) idealizaram um} teste de hemaglutinação, em que empregaram como antígeno hemá cias de carneiro sensibilizadas com antígeno gênero-específicos extraídos de uma cepa de leptospira aquícola, observando que apenas as imuneglobulinas do tipo $M$ tomam parte nessas reações. Os resultados obtidos pot CHANG \& FAINE ${ }^{12}$ (1974) com o antígeno preparado com o filamento axial de diversas linhagens de leptos piras, vieram também demonstrar que as reaçōes cruzadas ocorrem às custas de anticorpos do tipo IgM. Assim, é de se esperar que, as reações de aglutinação microscópica ou de fixação do comple mento com o emprego de antígenos heterólogos sejam mais preco ces, revelando deste modo os animais recentemente infectados.

Em relação à reação de fixação do complemento, cabe ainda salientar a ocorrência do fenomeno de zona aproxima damente 308 das reaçōes positivas, fenómeno esse também observá do e citado por outros autores 34,36 . Esse fenômeno segundo $A-$ MEIDA ${ }^{3}$ (1956) parece ser inerente a determinados sistemas de $\mathrm{f}_{\underline{i}}$ xaçāo do complemento, incluindo o sistema leptospirose, os quais fornecem uma curva de isofixação do tipo II. Existe assim, uma inibição 
da fixação do complemento em zonas de excesso de anticorpos pa ra uma dada quantidade de antígeno, considerada ótima quando do sada com o anti-soro específico. 


\section{CONCLUSOES.}

Face aos resultados obtidos pela metodologia em pregada, podemos concluir que:

6.1. A reação de fixação do complemento é mais precoce em re velar os animais reagentes na fase inicial da infecção, pois os anticorpos fixadores do complemento podem ser ob servados na circulaçäo sanguínea em títulos significati vos a partir do $4^{\circ}$ dia após a infecção experimental em 478 dos cāes inoculados com leptospiras patogênicas do sorotipo icterohaemorrhagiae e $53 \%$ dos cães inoculados com o sorotipo canicola. As aglutininas são observadas a partir do $7^{\circ}$ dia em $80 \%$ dos cães do $1^{\circ}$ grupo e em $53 q$ dos cães do $2^{\circ}$ grupo, em títulos iguais ou maiores que 100 .

6.2. As aglutininas persistem durante um período maior de tem po, sendo que $50 \%$ dos animais inoculados com o sorotipo icterohaemorrhagiae ainda apresentam anticorpos circulan tes no $56^{\circ}$ dia após a infecção experimental e $80 \%$ dos cães inoculados com o sorotipo canicola são reagentes no $63 \%$ dia, enquanto os anticorpos fixadores do complemento nāo mais são encontrados em nível significativo.

6.3. As estirpes Patoc I e Rufino não se prestam ao diagnósti co da leptospirose em cäes, pois não foram eficientes em revelar anticorpos circulantes em ambos os grupos experi mentais, em proporções que justifiquem o seu emprego co mo antígeno único. A baixa concordância entre os resul tados obtidos pelo emprego dessas cepas e os obtidos com o emprego de antígenoshomólogos não está relacionada ao período de tempo decorrido após a infecção.

6.4. A estirpe aquícola Buenos Aires é a que melhor se adapta ao diagnóstico da leptospirose em cães pelos sorotipo ic terohaemorrhagiae ou canicola, sendo a sua sensibilidade em detectar os reagentes a esses sorotipos de $87 \%$ e $80 \%$, 
respectivamente, na fase inicial da infecção, no período compreendido entre o $7^{\circ}$ e $28^{\circ}$ dias após a infecção.

6.5. A sensibilidade da estirpe Buenos Aires não é suficiente mente alta para se indicar o seu emprego como antígeno $\underline{\underline{u}}$ nico nas reações de soroaglutinação microscópica ou de fixação do complemento, mas recomenda-se incluí-la na ba teria de antígenos, devido à possibilidade de revelar os animais reagentes às leptospiras patogênicas na fase agu da da infecção, dando ao clínico informações suficientes para o inicio do tratamento. 


\section{REFERENCIAS BIBLIOGRAFICAS *}

1. ADDAMIANO, L. La utilizzatione di Leptospira biflexa nella siero diagnosi di Leptospirosi. In: SIMPOSIO NAZZIONALE SULLA LEPTOSPIROSI, 1, Atti. Pisa, 1962, p. 231-42.

2. ADDMANIANO, L. \& BABUDIERI, B. Water strains of leptospira in the serodiagnosis of human and animal leptospirosis. Bull. W1d H1 th Org., 39: 925-34, 1964 .

3. ALMEIDA, J. 0. Isofixation curves a method for standardizing quantitative complement fixation tests. J. Immuno1., 76: $259-63,1956$.

4. ALSTON, J. M. \& BROOM, J. C. Leptospirosis in man and ani mals. Edinburgh, E. \& L. Livingstone, 1958.

5. BERGEY'S manual of determinative bacteriology. 8 ed. Baltimo re, Williams \& Wilkins, 1974.

6. BESSEMANS, A. \& NELIS, P. apud OTSUKA, S. 34 p. 236.

7. BUERKI, F. An orienting study of animal sera for antibodies against Leptospira by mixed antigens in the complement fi xation reaction. II. Results in comparison to the agglu tination 1ysis reaction. 2. Immun. Forsch., 119: 333-43, 1960 .

8. BUKANTZ, S. C. Studies in complement fixation. II. Preser vation of sheep's blood in citrate dextrose mixture (Modi fied Alsever's solution) for use in the complement fixa tion reaction. J.Lab. c1in. Med., 31: 394-9, 1946.

9. CACCHIONE, B. A.; CASCELLI, E. S.; MARTINEZ, E.S. Leptospira biflexa Rufino. Su uso en el diagnostico de leptospirosis animal. Rev. Invest. agropec., serie 4, 8: 29-35, 1971 .

* De acordo com: ASSOCIAÇAO PAULISTA DE BIBLIOTECARIOS. Grupo de Bibliotecārios Biomédicos. Referências bibliográficas em ciências biomédicas. São Paulo, 1971 . 
10. CACChIONE, B. A.; CASCElli, E. S.; MARTinez, E. S. Avances en el diagnostico de leptospirosis animal por una prueba microscopica empleando un antigeno de $\underline{L}$. biflexa cepa Ru fino. Rev. Asoc. argent. Microbiol., 4: 3-7, 197.2.

11. CAMARgo, N. F.; EICHORN, E. A.; LEVINE, J. M.; TElEz GiRON, A. A complement fixation technique for Foot-and-Mouth di seases and vesicular estomatitis. In: ANNUAL MEETING OF AMERICAN VETERINARY MEDICAL ASSOCIATION, 87 th, 1950. Pro ceedings . P. 207-11.

12. CHANG, A. \& FAINE, S. Relative specificities of immunoglobu lins reacting with axial filament antigen of Leptospira. Aust. J. exp. Biol. med. Sci., 52: 639-46, 1974 .

13. COMBIESCO, D.; STURDZA, N.; SEFER, M.; RADU, J. Recherches sur les leptospirosis. Arch. roum. Path. exp., 17: 245$-50,1958$.

14. COMBIESCO, D.; STURDZA, N.; SEFER, M.; KLIPPER, A. Evolution des agglutinines dans les leptospiroses humaines, valeur de la reaction d'agglutination-lyse dans la detarmination du type Etiologique. Arch. roum. Pathol. exper., 19:202-9, 1960.

15. CORREA, M. O.A.; NATAlE, V.; SADATSUNE, T.; FlEURY, O. C. Va lor prático do uso de Leptospira semaranga Patoc I no diag nóstico das leptospiroses humanas. Rev. Inst. Med. trop. S.Paulo, 12: $284-7,1970$.

16. COX, C. D.; STROVER, R. C.; TREIK, R. W. Se rological studies on hemolytic antigen from leptospira. Proc.Soc. exp. Biol., New York, 98: 265, 1958 .

17. ELIAN, M. \& NICOARA, I. The use of Leptospira fiflexa Patoc antigen in field investigayions of leptospirosis. Bull. W1d H1th Org. , 34: 359-63, 1964.

18. FUCHS, G. H. Experience with L. biflexa antigens in laborato ry diagnosis of suspect cases of leptospirosis. 2bl.Bakt. Parasitkde, 209: 261-7, 1969. 
19. HAGIWARA, M. K. Leptospirose canina em São Paulo. São Paulo, 1974. (Dissertação de Mestrado - Faculdade de Saúde Püblí ca).

20. HANSON, L. E. Immunology of bacterial diseases with special references to leptospirosis. J.Amer. vet. med. Assoc., 170: $991-4,1977$.

21. HEGYESSEY, G. \& KUBINYI-SCHWNNER, M. Beitrag zur Laborato tiums-diagnostik der Leptospiren (Laboratory diagnosis of leptospirosis: The complement fixation test), Zbl. Bakt.I. Abt. Orig., 184: 471-77, 1962.

22. HERGT, B. Meaning of serotype Patoc (biflexa complex) for the diagnosis of leptospirosis by microscopic agglutination test. 2bl. Bakt. Parasitkde, 235: 506-11, 1976.

23. HODGES, R. T. A complement fixation test for the serologi cal diagnosis of leptospirosis in pigs experimentally in fected with serotype pomona. N. Z. vet. J., 21: 1-6,1973.

24. HODGES, R. T. \& RIS, O. R. Complement fixing and agglutinat ing antibodies responses and leptospiruria in calves ino culated with L. serotypes pomona, hardjo, copenhageni or ballum. N.Z. vet. J., 22: 25-30, 1974 .

25. KMETY, E. Betrachtungen zum Problem du paradoxen rektion und deren Bedeutung in der Serodiagnostik einiger Leptospiro sen. Zb1. Bakt.I.Abt. Orig., 170: 597-608, 1958.

26. LEPTOSPIRAL SEROTYPE DISTRIBUTION LISTS. According to host and geographic area. Atlanta, Ga. Department of Health, Education and Welfare, 1966.

27. LEPTOSPIRAL SEROTYPE DISTRIBUTION LISTS. According to host and geographic area. Supplement to 1966 publication Atlan ta, Ga. Departament of Health, Education and Welfare, 1975.

28. MAIllouX, M. Utilité de l'antigene biflexa patoc dans les serodiagnostics de leptospiroses. Ann. Inst. Pasteur. 112: $121-5,1967$. 
29. MARTIN, L. \& PETIT, A. apud TURNER, L. H. 50 . p. 882.

30. MENGES, R. M.; GALTON, M.M.; HABERMANN, R. T. Culture and se rologic studies on four dogs inoculated with two leptosni ral serotypes, Leptospira pomona and Leptospira canicola. Amer. J. vet. Res., 21: 371-6, 1960.

31. MORRIS, J. A. \& HOUSSAINI, S. N. Characterization of the an tibodies detected by the microscopic agglutination test for bovine leptospirosis. J. Hyg., Cambridge, 73: 425-32, 1974 .

32. NICOLESCO, M. \& LELUTIU, C. Diagnostic par la reaction du complement a $l^{\prime}$ aide d'un antigens unique dans le decele ment des leptospiroses animales. Arch. roum Path. exper. Microbio1., 26: 557-64, 1967 .

33. ORGANIZACION MUNDIAL DE LA SALUD. Grupo de Expertos em Pro blemas Actuales de las Investigaciones sobre Leptospiro sis, Moscu, 1966. Informes. Geneva, 1967. (Ser. Inf. tecn., 380).

34. OTSUKA, S. Complement fixation test for diagnosis of canine leptospirosis. I. Relation to agglutination lysis probe in natural cases. Igaku to Seibutsugaku (Med. Biol.), 32 : $236-38,1954$.

35. PALIT, A. \& GULASEKHARAN, J. Genus specific leptospiral an tigen and its possible use in laboratory diagnosis.J. Clin Path., 26: 7-16, 1973 .

36. PALIT, A. \& SHARMA, G.L. Comparison of microscopic agglutina tion, indirect haemagglutination and complement fixation tests in rabbit and buffalo calf immunesera for detection of leptospiral antibodies. Brit. vet. J., 127: 154-61,1971.

37. PETELIN, N.; CINCO, M.; MAGL IOCCHETTI-LOMBI, P. Comparative diagnostic significance of some water-Leptospirae for hu man leptospirosis. Trop. geogr. Med., 22: 245-9, 1970 . 
38. PINTO, A. A.; SANTA ROSA, C. A.; SAdATSUME, T.; Fleury, G.C. Comparative study between complement fixation and micros copic agglutination tests for leptospiral diagnosis. Rev. Inst. Med. trop. S. Paulo, 16: 28-31, 1974 .

39. POTT, A. W. \& DORNICK, C. G. T. The complement fixation test in the diagnosis of Weil's disease. J.Path. Bact., $\underline{43}$ : $367-72,1936$.

40. RIS, D. R. The failure of genus specific serological tests to detect leptospirosis in cattle and rabbits. N.Z. vet. J.. 23: $164-6,1975$.

41. ROBERTSON, A. \& BOULANGER, P. Comparison of the complement fixation test and the microscopic agglutination test (ag glutination lysis) for the detection of leptospiral sero group antibodies. Canad. J. comp. Med. vet. Sci., 27:11 $-20,1963$.

42. SANTA ROSA, C. A. Diagnóstico laboratorial das leptospiroses. Rev. Microbio1., 1: 97-109, 1970 .

43. SANTA ROSA, C. A. Estudo comparativo de algumas estirpes de leptospiras apatogênicas para o diagnóstico de leptospiro se animal. São Paulo, 1977. (Tese de Livre Docéncia - Fa culdade de Medicina Vetarinäria e Zootecnia da USP).

44. SANTA ROSA, C. A. s into, A. A. Reação de fixação do com plemento no diagnóstico de leptospirose animal. Emprego de um antígeno de amostra apatogênica. Arq. Inst. Biol., São Paulo, 41: 19-23, 1974 .

45. STURDZA, N.; ELIAN, M.; TULPAN, G. Diagnosis of human 1ep tospirosis by the complement fixation test with a single antigen. Arch. roum. Path. exper. Microbio1., 19: 571-82, 1960 .

46. STURDZA, N. E ELIAN, M. Comparative study of different strains of $\underline{L}$. biflexa as antigens for the complementfixation tests in leptospirosis. Arch. roum. Path. exp. Microbio1., 20: 33-41, 1961 . 
47. SzatalowiCZ, F. T.; GRIFFIN, T. P.; STUNKARD, J. A. The in ternational dimensions of leptospirosis. J.Amer. vet. med. Ass. , 155: 2122-33, 1969 .

4i. TAYLOR, P. L.; HANSON, L. E.; SIMON, J. Serologic, patholo gic and immunologic features of experimentally induced lep tospiral nephritis in dogs. Amer. J. vet. Res., 31: 1033$-49,1970$.

49. TRIGG, J.S. \& MARSHAK, R. R. Leptospirosis: a contemporary zoonosis. Ann. intern. Med., 79: 893-4, 1973.

50. TURNER, L. H. Leptospirosis. II. Serology. Trans. roy. Soc. Med. Hyg. 62: 880-9, 1968.

51. ULRICH, C. A. \& MAC ARTHUR, F. X. An improved method for production of anti-sheep hemolysin. J.clin. Path., 12: $84-5,1942$.

52. WOLFF, J.W. \& TURNER, L. H. Report of a meeting of a taxo nomic subcomitee on Leptospira. Int. Bull. bact.Nomencl., 13: $161-5,1963$.

53. WONG, M. L.; SHELTON KAPLAN, M. D.; DUNKLE, L. M.; STECKEN BERG, B. W.; FEIGIN, R. D. Leptospirosis: a childhood di sease. J.Pediat., 90: $532-37,1977$.

54. YANGER, R. H.; GOCHENOUR, W. S. Jr; WARNER, A. R.; WETMORE, P. W.: HALL, H. Complement fixation in diagnosis of hu nam leptospirosis. Fed. Preoc., 10: 425-35, 1951.

55. YASSUDA, P. H. Leptospirose em cães errantes da cidade de São Paulo, 1979. (Tese de Doutoramento - Instituto de C ências Biomédicas - USP). 